\title{
Applying community-based and Indigenous research methodologies: lessons learned from the Nuxalk Sputc Project
}

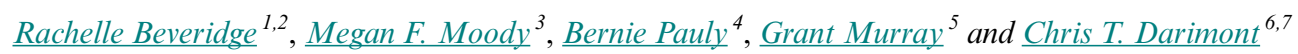

\begin{abstract}
In the face of ecological depletion on a global scale, Indigenous knowledges, priorities, and perspectives are increasingly applied in community and academic research intended to inform social-ecological decision making. Many academic researchers and decision makers have learned to solicit Indigenous knowledges using community-based research methods and participatory processes. However, Indigenous scholars and leaders are increasingly moving beyond these standard practices to apply Indigenous methodologies, engaging local epistemologies, and culturally relevant methods to produce respectful research outcomes in support of local priorities. We share experiences and learning from the Nuxalk Sputc (eulachon) Project to illustrate how an Indigenous research process was developed and applied by the Nuxalk Nation's Stewardship Office in Bella Coola, British Columbia (Nuxalk territory). This project documented, interpreted, articulated, and represented Nuxalk knowledge about eulachon (Thaleichthys pacificus) using an iterative, community-driven process informed by Nuxalk protocols and knowledge systems. We begin by detailing the project process, including project initiation, decision making, and community engagement processes, and methods of knowledge documentation, interpretation, articulation, representation, and sharing. Demonstrating that the Sputc Project's distinctly Nuxalk approach was key to its success, we discuss how engaging Nuxalk knowledges influenced our process from conception to completion, resulting in an emergent methodology that prioritized relational accountability, locally grounded methods of knowledge documentation and interpretation, respectful representation, and reflexivity. Based on our experience with the Sputc Project, we distinguish between Indigenous and communitybased methodologies, both in terms of their epistemological foundations and their orientation to the goals of decolonization and resurgence. We suggest that by considering and valuing Indigenous methodologies, researchers and decision makers can move toward authentically and respectfully engaging Indigenous knowledge and priorities, and ultimately, toward supporting Indigenous production, interpretation, articulation, and representation of knowledge in a contemporary context.
\end{abstract}

Key Words: community-based participatory research (CBPR); environmental management; eulachon; Indigenous methodologies; Nuxalk; research methods; social-ecological systems

\section{INTRODUCTION}

Considering different ways of knowing is integral to the conduct of social-ecological research. Indigenous peoples' priorities, perspectives, and knowledge are increasingly sought and valued in social-ecological research and decision making (Harris and Millerd 2010, Adams et al. 2014, von der Porten et al. 2015). Research is embedded in the context of existing power relationships and the choice of methodology is a political act (Brown and Strega 2005, Kovach 2017). With important implications for how research is conducted from conception to completion, the choice of methodology informs how knowledge is sought, documented, interpreted, articulated, and represented. For example, community-engaged methods and participatory processes are often employed and even recommended in collaborative research with Indigenous communities in an effort to center community voices (Canadian Institutes of Health Research et al. 2014, Tobias et al. 2013, Moore et al. 2017). Frameworks describing public or Indigenous participation in social-ecological research, including variants of communitybased research, have been extensively elaborated (Wallerstein and Duran 2006, Wulfhorst et al. 2008, Shirk et al. 2012). However, such methods sometimes fall short in their engagement of Indigenous knowledge (Nadasdy 1999, 2005, McGregor 2004, 2009, Kindon 2008, Castleden et al. 2012, de Leeuw et al. 2012) or in establishing Indigenous leadership and decision making (von der Porten et al. 2015, Brunger and Wall 2016, Castleden et al. 2017). Therefore, it is increasingly recommended that research be led by Indigenous people and driven by their priorities (McGregor 2004, Simpson 2014, 2017), and informed by decolonizing and Indigenous methodologies (Kovach 2005, 2009, Wilson 2008).

Although Indigenous methodologies are occasionally referenced by community-engaged researchers in environmental management (de Leeuw et al. 2012, Latulippe 2015a, von der Porten et al. 2019), there are few published examples of their application in these settings or discussions of how they differ in practice from other forms of community-based participatory methodologies. Seeking to support a movement beyond Indigenous 'participation' in western research, we detail a project successfully led by Indigenous knowledge systems, values, and priorities, and informed by Indigenous methodologies, detailing how it was conducted and what made it distinct from other communityengaged processes. We employ our learning from this project to distinguish between Indigenous and community-based research methodologies.

Initiated and led by the Nuxalk Stewardship Office in Bella Coola (in what is now known as British Columbia, Canada), the Nuxalk Sputc Project aimed to adopt a Nuxalk process to document and share Nuxalk knowledge about eulachon (Thaleichthys pacificus) for use by Nuxalk leadership and community members in the

${ }^{1}$ University of Victoria, Victoria, British Columbia, Canada, ${ }^{2}$ University of British Columbia, Vancouver, British Columbia, Canada, ${ }^{3} \mathrm{Nuxalk}$ fisheries biologist, Victoria, British Columbia., Canada, ${ }^{4}$ Canadian Institute for Substance Use Research, School of Nursing, University of Victoria, Victoria, British Columbia, Canada., ${ }^{5}$ Duke University Marine Lab, Duke University, Durham, North Carolina, USA., ${ }^{6}$ Department of Geography, University of Victoria, Victoria, British Columbia, Canada, ${ }^{7}$ Raincoast Conservation Foundation, Bella Bella, British Columbia, Canada 
management of eulachon. As detailed below, eulachon are a cultural keystone species that form the backbone of Nuxalk health and identity but have been functionally absent in Nuxalk territory for over 20 years. Because of the role of eulachon in the larger context of Nuxalk wellness and strength, there was a high level of interest on behalf of Nuxalkmc to conduct the Sputc Project as a means to address ongoing threats to eulachon knowledge loss and management jurisdiction. Engaging a uniquely Indigenous (Nuxalk) research approach, the Sputc Project constituted an important opportunity to examine the application of Indigenous-led methodologies as an example for researchers and practitioners in other contexts.

Indeed, our focus is on research methodology, rather than the specifics of eulachon management though this is detailed in (Beveridge et al. 2020). The writing of this paper was led by a non-Nuxalk doctoral candidate in collaboration with Nuxalk project partners and non-Indigenous academic mentors. Following a description of community-based and Indigenous methodologies in environmental management and an elaboration of the project context, we outline the Sputc Project process and discuss how applying a Nuxalk approach influenced project methods. We then consider the project process to enable distinction between Indigenous and other community-engaged methodologies and their relationship to decolonizing and resurgent goals.

\section{Background and theory}

Whether or not they are acknowledged, knowledge systems and related theories inform every research methodology (Brown and Strega 2005, Kovach 2009, Creswell 2012). Community-based and Indigenous research methodologies are based on different knowledge systems and theories (Smith 1999, Kovach 2009), which may or may not be combined. For millennia, Indigenous knowledge and related systems of governance have supported sustainable systems of resource management on Canada's west coast (Turner and Berkes 2006, Lepofsky and Caldwell 2013, Gauvreau et al. 2017, Turner 2020) and throughout the world (Menzies 2006, Bohensky and Maru 2011, Berkes 2012). Indigenous knowledge refers to the unique knowledge systems held, used, and maintained by Indigenous peoples. As detailed elsewhere, Indigenous knowledge is at once metaphysical and pragmatic, inseparable from place (lands and waters), people, practices, and language (Battiste and Henderson 2000, McGregor 2004, 2009, Archibald 2008, Wilson 2008, Simpson 2014, 2017). According to Margaret Kovach (Kovach 2009, 2017), each unique Indigenous knowledge system comprises epistemologies and theory-principles. Epistemologies describe ways of knowing, including assumptions about the nature of knowledge and knowledge production, i.e., defining what kinds of knowledge are possible (Kovach 2017). Indigenous epistemologies imply fundamentally relational ways of knowing and being (McGregor 2004, Wilson 2008, Kovach 2009, Simpson 2017), based in worldviews that include holism, interconnection, and flux/fluidity or circularity (Louis 2007, Hart 2010, Kovach 2017). Theoryprinciples are Indigenous teachings, including philosophy and values and practices that guide relationships with people, land, ideas, and the cosmos (Kovach 2017). Among others, these may include the values of reciprocity, responsibility, and respect (Weber-Pillwax 2001, Hart 2010, Artelle et al. 2018).
Since colonization, the expertise of Indigenous peoples has been sidelined, and the methods used by external researchers to solicit, appropriate, and represent Indigenous knowledge in resource management have too often been problematic, extractive, and even harmful (Nadasdy 1999, 2003, Smith 1999, Simpson 2001, McGregor 2004). Whereas western or scientific research methods certainly have a place in upholding Indigenous priorities, how they are used (and by whom) matters (Adams et al. 2014). Recognizing this, scholars in environmental management and beyond are beginning to decolonize their research practices, seeking less extractive ways to uphold Indigenous voices and priorities in decision making and research (Smith 1999, von der Porten et al. 2015, 2019, Carlson 2016, Smith et al. 2016, Castleden et al. 2017, de Leeuw and Hunt 2018). Further, supported by a rapidly evolving legal and regulatory context (Harris and Millerd 2010, Kotaska 2013, von der Porten et al. 2016, Low 2018), Indigenous people are increasingly leading research in their own communities, based on their own knowledge and driven by their priorities (Adams et al. 2014, Housty et al. 2014, von der Porten et al. 2016, 2019, Castleden et al. 2017, Jones et al. 2017). Such efforts have resulted in increasing application of Indigenous research methodologies distinct from those used in communitybased research (Smith 1999, Kovach 2009).

Given the recognized importance of using research methodologies that respectfully engage Indigenous knowledge, ethics, and priorities, Canadian funding authorities recommend using community-based participatory research methods (CBPR) for conducting research with Indigenous communities (Canadian Institutes of Health Research et al. 2014, Moore et al. 2017). With foundations in critical, feminist, and anti-oppressive theories, CBPR aims to challenge the processes of knowledge production, attending to power structures and centering marginalized voices (Israel et al. 1998, 2005, Wallerstein and Duran 2006, Darroch and Giles 2014). Community-engaged research takes many forms and may be characterized in a diversity of ways (Wilmsen 2008, LaVeaux and Christopher 2009, Wallerstein and Duran 2010, Shirk et al. 2012). For the purposes of this research, we refer to community-based research methods and approaches in general, but largely draw on literature and experience related to CBPR, as opposed to other public or participatory methodologies (e.g., Wilmsen 2008, Shirk et al. 2012). We use the terms approach and methodology interchangeably.

Community-based research approaches have much to contribute to research that is responsible, respectful, reciprocal, and relevant (Louis 2007, LaVeaux and Christopher 2009, Castleden et al. 2012, de Leeuw et al. 2012, Tobias et al. 2013). In attending to marginalized voices and power structures, CBPR has been recommended as (and embraces) a more respectful research approach with Indigenous people. However, it is ultimately based in western ways of knowing (e.g., critical or feminist theory) and can only go so far in informing methodologies rooted in Indigenous knowledge systems. Many suggest that without due attention to their limitations, application of community-based research methods in Indigenous contexts can be problematic (Stiegman and Castleden 2015, Brunger and Wall 2016, Moore et al. 2017). Operationalization of the tenets or principles of community-based research (described in detail elsewhere) is highly subjective (LaVeaux and Christopher 2009, Castleden et al. 2012, de Leeuw et al. 2012, Tobias et al. 2013, Coombes et al. 
2014, Brunger and Wall 2016, Moore et al. 2017), and communitybased work is often conducted without challenging western epistemological frameworks or underlying assumptions about the nature of knowledge production or ownership (Smith 1999, Brown and Strega 2005, Kovach 2009, 2017, Darroch and Giles 2014).

Indeed, even well-executed community-based approaches may be insufficient to capture the nuances and complexity of Indigenous perspectives (Nadasdy 1999, 2003, McGregor 2004, 2009) and might additionally impose significant burdens on Indigenous communities (Castleden et al. 2012, 2017, de Leeuw et al. 2012, Brunger and Wall 2016). In environmental management, this is evident in studies emphasizing Indigenous knowledge integration into western research frameworks (Nadasdy 1999, Bohensky and Maru 2011, Evering 2012, Hill et al. 2012) or using "parachute" research approaches (Brant Castellano 2004, Castleden et al. 2012).

Given these limitations, some scholars advocate employing Indigenous methodologies and related research frameworks to guide culturally embedded research methods, protocols, and practices that are accountable to Indigenous communities and knowledge systems (Louis 2007, Wilson 2008, Kovach 2009, 2017). Despite their differences in epistemological origin, Indigenous methodologies are often practically aligned with community-engaged research approaches (Smith 1999, Creswell 2008, Denzin et al. 2008, Wilson 2008, Kovach 2009, LaVeaux and Christopher 2009, Easby 2016). However, unlike communitybased methodologies, which are founded in western systems of knowledge (Kovach 2017), Indigenous methodologies explicitly employ distinct, culturally specific knowledge systems to inform research methods and processes (McGregor 2004, Louis 2007, Wilson 2008, Kovach 2009). Pushing back on dominant research paradigms, Indigenous methodologies create space for particular, place-based Indigenous worldviews as a legitimate way to approach a research question. As such, their respectful application by scholars not well versed in Indigenous ways of knowing is limited (Carlson 2016, Smith et al. 2016).

Employing Indigenous methodologies requires a fundamental redefinition of what research is and how it is conducted, including assumptions about who produces knowledge, for whom, how, and for what purpose (Brown and Strega 2005, Kovach 2009). Indigenous methodologies are informed by Indigenous resurgence movements, which are concerned with turning toward ancestral knowledge, law, and governance as sources of Indigenous power (Alfred 2005, Simpson 2008, Corntassel 2012, Coulthard 2014, Asch et al. 2018). At once cultural and political, resurgence is a process of Indigenous theorizing, writing, organizing, and thinking that is "generated through place-based practices - practices that require land" (Simpson 2017:49).

In practical terms, Indigenous methodologies emphasize attention to diverse knowledge sources, application of local protocols and practices, and community engagement based in respect, reciprocity, and responsibility (Battiste 2005, Louis 2007 , Kovach 2009, 2017, Coombes et al. 2014, Latulippe 2015a, Chalmers 2017). In particular, Indigenous scholars highlight that drawing on the interrelated principles of relational accountability, respectful representation, and reflexivity enables Indigenous knowledge and priorities to guide choices throughout the research process (Absolon and Willett 2004, Louis 2007, Wilson 2008, Kovach 2009, 2017). According to Margaret Kovach, "relationship is how we do Indigenous methodology" (Kovach 2017:223), as expressed through mutual relationships of trust, application of ancestral protocol and ethics, and culturally relevant methods of learning and sharing. According to some Indigenous methodology specialists, relational values indicate that the purpose of knowledge (production) "is not to explain an objectified universe, but to understand one's responsibilities and relationships and to engage in mutual reciprocity" (Shaw et al. 2006, Legat and Barnaby 2012, Latulippe 2015b:5), strengthening the web of relationships (Wilson 2008). Based on a fundamental understanding of the world as interconnected and whole, the principle of relational accountability calls attention "not only to the relationships...between researchers and research subjects, but also to the networks of relations through which a researcher (and knowledge itself) is constituted and held accountable" (de Leeuw et al. 2012:182). The principle of respectful representation requires considering how the people, places, events, and phenomena being researched are represented, with attention to protocol and ownership of knowledge (Wilson 2008, Kovach 2009, Beveridge 2019). The practice of reflexivity supports awareness of both relationships and responsibilities. These principles are best enacted through knowledge seeking and sharing methods that are inclusive of local ways of knowing and being, including place-based protocols, experiences, and voices, enabling situated, culturally relevant methods and outcomes (Absolon and Willett 2004, Louis 2007, Coombes et al. 2014, Kovach 2017). Often, they involve an element of narrative or story, which encourages relational interpretation or witnessing (Absolon and Willett 2004, Thomas 2005, Archibald 2008, Kovach 2009, 2017).

In many ways, Indigenous and community-based research methodologies share common goals and practices, even if they originate from different worldviews and theories. Both may value reflexive, relational, and interpretative process alongside content (Kovach 2005, 2009, Wilson 2008, LaVeaux and Christopher 2009). Indigenous methodologies further overlap with community-based approaches in that they are iterative, situated, and responsive, valuing accountability, responsibility, and respect throughout the research process (Kovach 2009, LaVeaux and Christopher 2009, Easby 2016). However, community-based and Indigenous methodology literatures are rarely cross-referenced, or are poorly distinguished (Latulippe 2015a, Castleden et al. 2017), a reality attributed to differences in their orientations to indigeneity and related use of language (Easby 2016). Because community-based and Indigenous methodologies are epistemologically, theoretically, and politically distinct, neither is universally applicable; community-based methods may not be sufficient to conduct respectful research in Indigenous contexts, while Indigenous methodologies are not appropriate for use by most non-Indigenous people (Kovach 2009, de Leeuw et al. 2012, Latulippe 2015a, Carlson 2016). This does not preclude settler researchers from respectfully engaging Indigenous priorities and perspectives to push the envelope of community-based research practice; indeed, so doing is an ethical and relational necessity (Irlbacher-Fox 2014, Carlson 2016). Given their theoretical and practical commonalities, mixing Indigenous and communitybased is entirely acceptable to many Indigenous methodology 
scholars (Kovach 2009, Evans et al. 2014). However, Margaret Kovach (2009) underlines that epistemological transparency is necessary to avoid subsuming Indigenous methods under western approaches and theories, or vice versa, especially when there is overlap between approaches (Kovach 2009).

Aligned with Borrows and Tully's concepts of robust resurgence and transformative reconciliation, we aim to support resistance to unjust and inequitable relationships (in this case, research relationships) as demanded by a decolonizing perspective (Borrows and Tully 2018). We employ the term "decolonizing" as a verb describing a sustained goal, intent, or action, grounded in real Indigenous interests and concrete action (Tuck and Yang 2012). Decolonizing research addresses the specific realities of settler colonialism, including historical context, legal rights, land issues, and colonizing practices, and aim to disrupt or subvert them "in order to push back against colonial institutions to make space for Indigenous resurgence" (Carlson 2016:9, Smith et al. 2016), including those related to research methodology and practice. It is our understanding that although they may be decolonizing in function, Indigenous research methodologies are fundamentally informed by resurgent thinking, in that they are founded in Indigenous ways of knowing and related theories (Kovach 2009). Meanwhile, community-based methodologies, based on western research approaches, are more likely to be decolonizing, in that they challenge power relationships and center Indigenous voices (Darroch and Giles 2014).

Indeed, epistemological transparency with regard to the theoretical grounding of research methodologies is key to supporting respectful research with (and by) Indigenous people. However, whereas Indigenous peoples' leadership in environmental research and practice is increasingly solicited and upheld (Adams et al. 2014, von der Porten et al. 2016, 2019), there remain few examples of the application of Indigenous methodologies in this context. Further, given the primacy of theoretical and epistemological considerations for the conduct of research, there is relatively little guidance available to researchers about the pragmatics of distinguishing between, choosing among, and applying Indigenous versus community-engaged research approaches (Latulippe 2015a, Carlson 2016, Easby 2016), or their respective relationships to the theories and goals of resurgence or decolonization. In this spirit, we consider community-based and Indigenous methodologies as complementary and potentially overlapping approaches, informed by Indigenous and/or western research theories. Through the example of the Nuxalk Sputc Project, we share an example of how appropriate engagement of Indigenous knowledge using a mixed Indigenous and communitybased research approach might support Indigenous goals of decolonization and resurgence in the context of environmental management and beyond.

\section{Project context}

The Sputc Project was based in the remote coastal community of Bella Coola, in the territory of the Nuxalk Nation. In Canada, First Nations are one of three recognized legal categories of Indigenous peoples (alongside Inuit and Métis) under the federal Indian Act. Sputc is the Nuxalk word for eulachon, a forage fish that spawns in glacier-fed rivers of the west coast of North America, including the central coast of British Columbia (see Fig. 1). Until recently, Nuxalkmc (the Nuxalk people) had a thriving relationship with sputc. A cultural keystone species (Garibaldi and Turner 2004), eulachon remain vital to Nuxalk well-being (Moody 2008, Haggan 2010) primarily as a food source but are also prized for their nutrient content and for their use in the production of sluq or grease, a highly valued oil that is traded between First Nations throughout the province (Kuhnlein et al. 1996; see Figs. 2, 3). Indeed, eulachon-related knowledge and practices (e.g., fishing, canoeing), relationships and connections (e.g., to lands and waters, community, and ancestors), and responsibilities and identities (e.g., fisherman, greasemaker, guardian) are all intricately tied to Nuxalkmc well-being and identity (Beveridge 2019).

Fig. 1. Nuxalk eulachon (Thaleichthys pacificus) rivers: black dots indicate rivers where eulachon were historically harvested by Nuxalkmc and/or where significant eulachon runs are known to have occurred in Nuxalk territory.

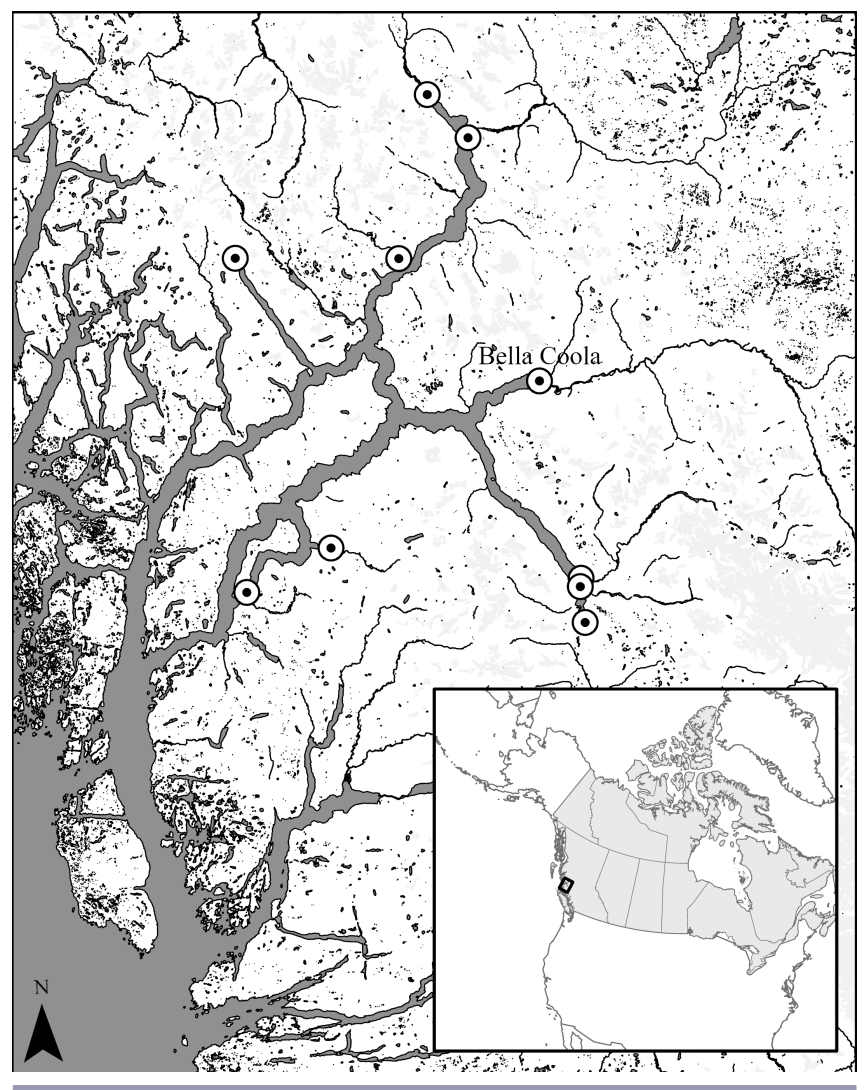

Nuxalkmc's relationship to eulachon is maintained by an ancestral system of knowledge and governance that has supported a healthy social-ecological system in the region for generations (Hilland 2013, Lepofsky and Caldwell 2013). The Nuxalk Nation constitutes an amalgamation of four culturally distinct regional groups, and Nuxalk people hold a diversity of knowledges, perspectives, and opinions. Although it is beyond our scope to describe this system in detail, it is important to note that the ancestral governance system is led by hereditary leaders called Stataltmc. Stataltmc act as house representatives for their immediate and extended family. According to Nuxalk (and Canadian) law (Supreme Court of Canada 1997, Hilland 2013), 
Stataltmc have authority to make decisions related to use of the lands, waters, and associated resources for which they hold responsibility.

Fig. 2. Eulachon (Thaleichthys pacificus) from the Nass River fermenting in a stink box in preparation for making sluq (eulachon grease).

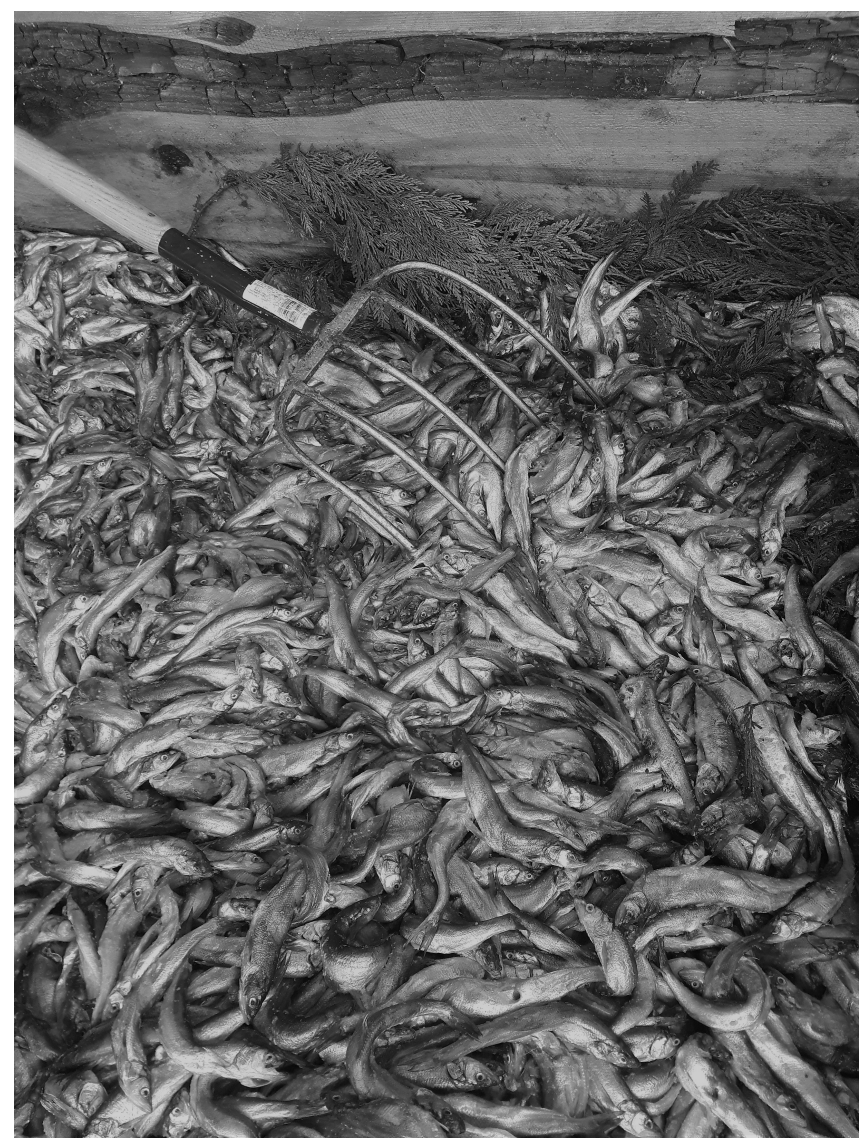

Although the hereditary governance system and related environmental management were certainly hindered by colonial impacts, locally known as the four modern catastrophes (smallpox, potlatch ban, residential school, reserve system; Snxakila 2014, personal communication), eulachon were not subject to the same levels of exclusion and dispossession as other fisheries in the region, e.g., salmon (Newell 1993, Harris 2001). Indeed, central coast eulachon fisheries were exclusively managed by Indigenous people throughout the region, such that eulachon are viewed by Nuxalkmc as an Indigenous fish, relatively untouched by colonialism (Beveridge 2019, Beveridge et al. 2020).

However, rights to manage and use eulachon were interrupted in 1999, when eulachon failed to return to the rivers of B.C.'s central coast. The fish have not reappeared to the Bella Coola River in harvestable numbers since that time. Though explanations for their disappearance vary, Nuxalkmc know that eulachon from the region were taken as bycatch by an expanding shrimp trawling industry (Moody 2008, Hilland 2013). As such, Nuxalkmc see the federal fisheries management system as having failed in its fiduciary duty to protect eulachon and Nuxalk fishing rights and understand it to have undermined existing management authority. Meanwhile, Nuxalkmc continue to claim de facto jurisdiction over their management (Hilland 2013).

Fig. 3. Sluq, Nuxalk eulachon (Thaleichthys pacificus) grease, being poured into jars for storage.

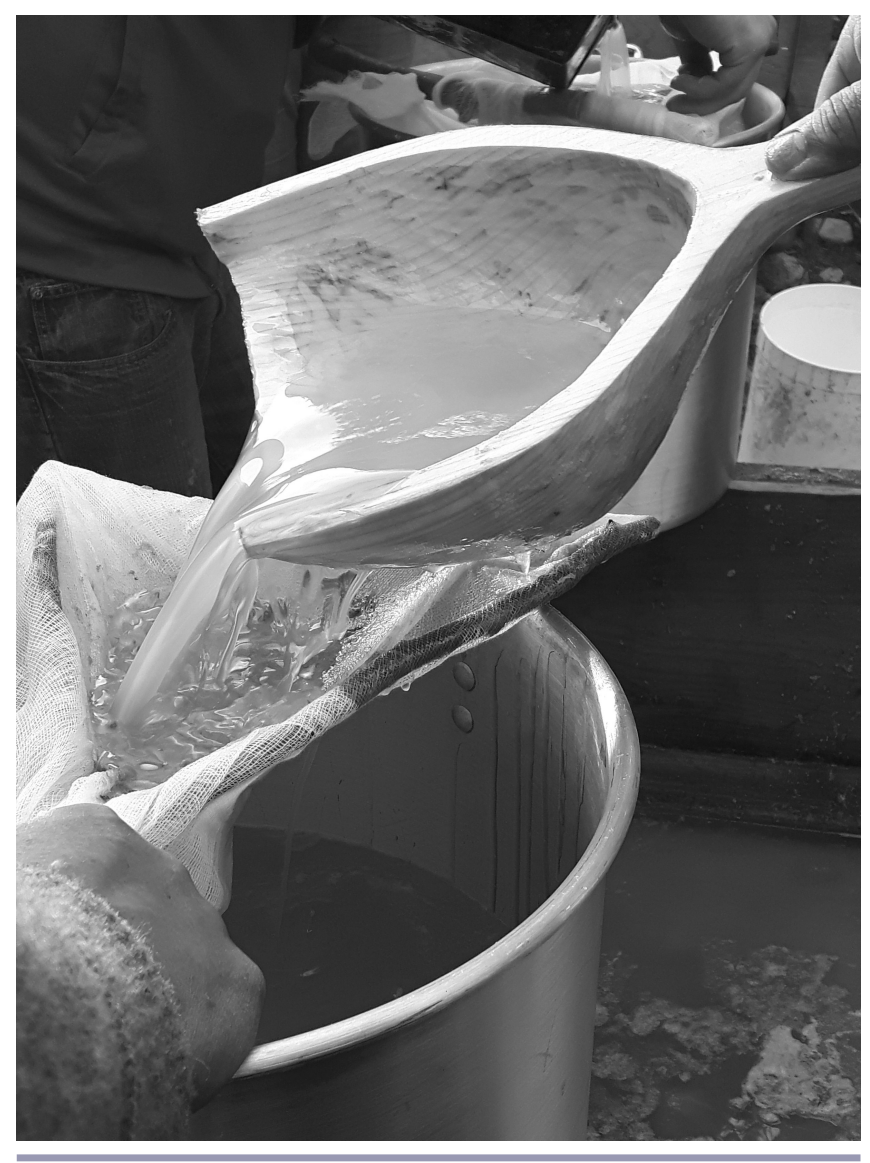

After almost 20 years without eulachon, many Nuxalkmc are concerned about the loss of eulachon-related knowledge and are demanding action based on Nuxalk knowledge and priorities (Senkowsky 2007). More recently, the need for action has been stressed by the potential listing of eulachon under the Canadian federal Species At Risk Act (SARA), which threatens to further undermine Nuxalkmc's de facto jurisdiction over the management of future eulachon fisheries in Nuxalk territory by seeking to regulate local use and access to the fish (e.g., via permitting; Hilland 2013, Beveridge et al. 2020). Nuxalkmc therefore recognize a need to document existing knowledge about eulachon values and stewardship, and to reiterate the foundations of Nuxalk eulachon management authority.

Based on this local demand, the Nuxalk Sputc Project was initiated and driven by the Nuxalk Nation's Stewardship Office in 2014 with the goals of: (1) documenting and sharing ancestral knowledge about eulachon history, values, and management with Nuxalkmc; (2) engaging Nuxalkmc and moving toward community agreement on eulachon management priorities; and (3) learning about, upholding, and applying Nuxalk governance and decision-making structures and processes. From its inception, 
the Sputc Project was intended to be informed by Nuxalk ways of knowing, including cultural teachings, ancestral decisionmaking practices, and governance protocols. Further, the knowledge produced by the project was intended for use by Nuxalkmc, including Nuxalk managers, leaders, educators, and the community at large, to restore and steward sputc, not for use/ interpretation by non-Nuxalk to manage sputc. It focused on documenting, interpreting, articulating, representing, and sharing knowledge within the Nuxalk community in a manner congruent with Nuxalk knowledge systems. This process provided context for learning and capacity building in the development of a uniquely Nuxalk research methodology, with lessons more broadly applicable to other research contexts.

\section{RESEARCH METHODS}

We intend to share applied learnings related to the theoretical and practical aspects of choosing and conducting research with Indigenous research partners. Based on extensive participation, experience, observation, and reflection by the authors, this work is based on critical and decolonizing theories (Smith 1999, Brown and Strega 2005) and an interpretive research approach. Although informed by the authors' participation in an Indigenous research project, the work is based primarily on the worldview of the first author, using an analytic method rooted firmly in western academic traditions, and intended for a diverse international audience. As such, the methods are distinct from the Indigenous (Nuxalk) methods of representing and relating knowledge employed by the Sputc Project.

Before the outset of the doctoral research upon which this work is based, a number of permissions and approvals were obtained, based on ethical principles outlined by both community-engaged and Indigenous researchers (Kirkness and Barnhardt 1991, Schnarch 2004, Louis 2007, LaVeaux and Christopher 2009, Castleden et al. 2012, Adams et al. 2014, Canadian Institutes of Health Research et al. 2014, First Nations Information Governance Centre 2014). First, permission was obtained from Stataltmc, the hereditary leaders and decision-making authorities over Nuxalk territory. Technical research agreements were signed with the Nuxalk Stewardship Office, which takes direction from Stataltmc and provides technical support for decision making by Nuxalk leadership. Approval by Band Council Resolution was also obtained as a requirement of university ethics, whose approval was also obtained through the University of Victoria's REB (protocol \# 14-075, 2014-2019). Because the limitations of research ethics' requirements in Canada as they pertain to Indigenous research have been well documented (e.g., Stiegman and Castleden 2015, Moore et al 2017), our goal was to create agreements that went beyond institutional requirements. Specifically, our agreements established mutual understandings related to project process and outcomes, highlighting the importance of relationship, responsibility, relevance, and reciprocity, established clear expectations and communication, and created a set of resource documents for use by other researchers.

This research was intended to build on, and uphold, knowledge generated by Nuxalk eulachon researchers (Moody 2008, Hilland 2013) and other documented sources of Nuxalk knowledge (e.g., ethnographic accounts). As part of her doctoral research, the first author recorded over 350 pages of minutes and observational fieldnotes taken throughout the project process from initiation to completion. These notes captured observations and insights from advisory meetings, informal conversations with community members, community events, feasts, and ceremonies, as well as reflections of participants and community members after project completion. These materials were reviewed and annotated by the first author in relation to the methodological elements of the work. In an iterative process, emergent themes and learnings were developed through a series of conversations with the second author.

The Sputc Project was funded by private foundations and other non-profit sources, while this work and related academic products (including a doctoral dissertation) were supported by academic funding sources. As a result, this research was subject to academic expectations and necessitated engagement with the western academic tradition, with requirements for literature citations and peer reviewers likely far removed from the local context.

\section{THE SPUTC PROJECT PROCESS}

The sections below provide details of the Sputc Project implementation, elaborating on how Nuxalk ways of knowing influenced the project process. Further analysis of the project as a research process is elaborated in the discussion.

\section{Initiation: permissions and protocols}

The Sputc Project was originally conceived by the 2013-2017 Nuxalk stewardship director (second author, MM) to inform the creation of a Nuxalk eulachon stewardship plan. The Nuxalk Stewardship Office initiated and led a community-engaged process intended from its inception to be informed by Nuxalk ways of knowing and being, including ancestral decision-making practices and governance protocols. This intent served as a touchstone throughout the project, guiding research design and decisions. Importantly, project initiation coincided with the rekindling of community-driven ancient eulachon welcoming ceremony and the raising of a carved pole to honor the eulachon (Thompson 2014). These events were essential to providing the project momentum and validity in the eyes of the community. Now an annual event, the eulachon ceremony serves as a reminder to Nuxalkmc of their relationship with, and responsibility to, this precious fish. Each year, the pole, representing Raven when he first brought cedar to the valley, is re-dressed in a fresh woven cedar cape, and an ancient song, dance, and ceremony reaffirm the place of the fish in Nuxalkmc histories and lives (see Fig. 4).

Engagement of Nuxalk governance processes and protocols was an essential element of the Sputc Project. For example, the project team individually visited each of the approximately 20 Stataltmc to approve project initiation and advise on project design. As a result, the project had broad community agreement according to the Nuxalk governance system from its inception, giving the project legitimacy to operate. Prioritizing time for one-on-one meetings with Stataltmc demonstrated an understanding of Nuxalk community authority, the importance of family relationships, and a commitment to engage ancestral governance and decision-making processes. Pre-existing relationships with key political and cultural knowledge holders was essential to this commitment. 
Fig. 4. Nuxalk sputc (eulachon, Thaleichthys pacificus) pole erected during the first annual eulachon ceremony. Re-dressed in cedar regalia every year, the pole depicts Raven in human form bringing the first eulachon to the Bella Coola River.

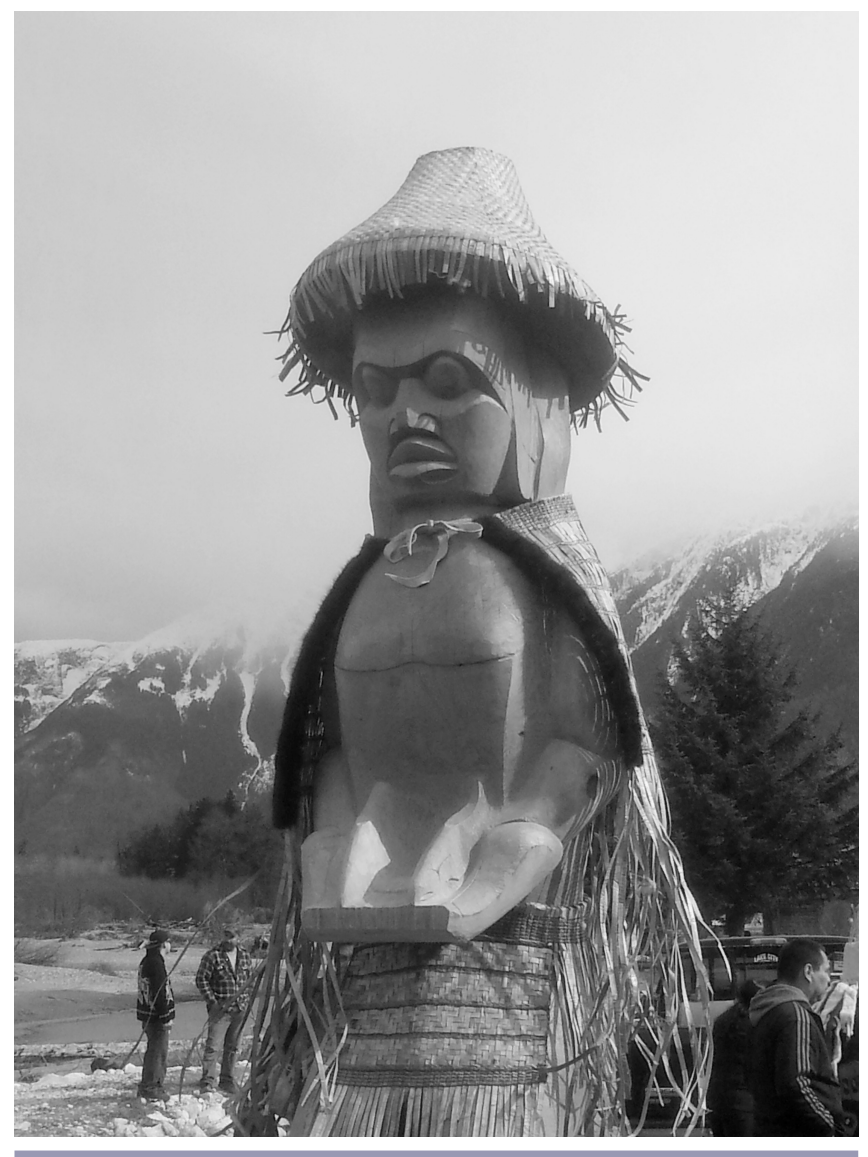

The project team and decision making

After obtaining permissions from community authorities, the project team sought to engage a broad cross-section of Nuxalkmc to direct the project. After an initial round of community bulletins and an open-house event, Nuxalkmc were invited to join a technical advisory committee to guide the overall project design, implementation, and outcomes. Stataltmc were specifically asked to send representatives to advisory meetings, which were convened approximately bi-weekly over the first six months of the project. A Nuxalk co-researcher was hired to support project logistics and relationship building, and knowledgeable cultural and language advisors were identified. Following this initial engagement process, the core project team was created, comprised of project leaders, a Nuxalk co-researcher, a project (technical) advisory committee (four core and twelve occasional), additional cultural and language advisors, and Stewardship Office staff. All project team members resided in the community throughout the project. The fact that the project team was primarily made up of Nuxalk members was essential to the project's success and its connection to the community. This project team informed all major decisions related to the project, including: whom to involve in the project and how to engage the community; what content to include, in what form; and how to represent and share knowledge gathered (including the design of final project outcomes).

Throughout the project, day-to-day project decisions were made by the project team and approved by the Stataltmc, and Nuxalk protocols for meetings, gatherings, and discussions were followed. Advice was given through both formal meetings and informal conversations, and recognized according to Nuxalk protocol through the presence of food and/or stipends for participating, witnessing, and advising. Actively following the guidance of the project team on an ongoing basis ensured that diverse Nuxalk knowledge and perspectives guided the project as it evolved, and that the project outcomes were accessible and meaningful to a broad range of Nuxalkmc. This process also provided those involved an opportunity to learn about and apply Nuxalk knowledge systems and ancestral decision-making processes, practices, and institutions, increasing Nuxalk governance capacity and understanding.

Although essential to the project, engaging Nuxalk protocol within both traditional and Band Office systems was also a challenge. Clear research processes and protocols needed to be developed within the Stewardship Office. The project team also spent a great deal of time in conversation with knowledge holders learning traditional Nuxalk protocols before considering implications and adapting them to the context of the project. This meant developing the capacity to listen, learn, and adapt methods; without connections and long-term presence in the community, applying Nuxalk protocol to this extent would have been even more difficult.

\section{Learning and sharing about sputc: knowledge documentation, interpretation, and representation}

As the project progressed, the project team began to gather, review, and learn from existing Nuxalk knowledge sources, including archival documents, ethnographic material, videos, reports, and academic studies. Academic reports (Mack 2006) and theses (Moody 2008, Hilland 2013) by Nuxalkmc, interviews from a prior eulachon traditional ecological knowledge (TEK) study (Winbourne 2002) and recordings of deceased elder knowledge holders were also accessed for the purposes of the project. This background research ensured that the work of previous researchers was respected, and that the project team was adequately prepared for in-depth conversations with knowledgeable community members (e.g., to avoid asking questions with widely known answers), such that further exchanges could be meaningful and mutually beneficial. Indeed, efforts were made throughout the project to minimize interview burnout and other undue demands on community capacities and resources.

Alongside a Nuxalk co-researcher, the first author conducted semi-structured interviews with willing Nuxalk knowledgeholders identified by the project team and associated Nuxalk members. In total, 8 men and 4 women over the age of 50 were interviewed for 1-2 hours covering topics including eulachon use and values, fishing, preservation, trade, grease-making practices, river stewardship, and governance. An additional five Nuxalkmc knowledge-holders refused permission for their recorded interviews to be used for academic research. This reticence may have been exacerbated by the presence of an outsider (first author- 
researcher), in combination with this person's lack of developed relationships at the onset of the research process. It was also clear that Nuxalkmc associated interviews with prior extractive research processes, and worried that shared knowledge would be misinterpreted or misapplied. Reflecting long-standing issues with unilateral knowledge extraction in Indigenous research (Nadasdy 1999, Smith 1999, Simpson 2001), the project team also found that the formal interview process lacked congruence with open-ended, conversational modes of knowledge sharing grounded in Nuxalk ways of knowing. This was evidenced by Nuxalkmc's apparent discomfort with interviews and expressed mistrust of this research modality. Given this context, we abandoned interviews altogether in favor of informal exchanges, community events, and a more culturally relevant research process based on the development of genuine, reciprocal relationships and ongoing presence in the community.

This locally grounded approach provided momentum to the project. Continued involvement in ceremony, cultural events, and land-based practices (e.g., revival of grease-making, using eulachon from rivers beyond Nuxalk territory) were also central to our learning. As trust and personal relationships were strengthened, several key knowledge holders became ongoing collaborators on the project. A greater breadth and diversity of Nuxalkmc volunteered stories and personal accounts of their experience of eulachon, as well as related archival photo, video, and audio materials. By the end of the project, the project team had one-on-one conversations with 60 knowledge holders and interacted with at least 180 of approximately 800 Nuxalkmc over the age of 14 in the Bella Coola Valley through community events, workshops, and elders' luncheons.

To clarify past and future eulachon fishing practices and management priorities, the project team also convened a workshop in November 2017 to learn about Nuxalkmc perspectives on future fishing and management priorities. The day-long workshop was attended by 21 leaders, fishers, and interested community members. After viewing images and quotes related to Nuxalkmc eulachon fishing, those present sat in small groups to discuss who, what, where, and how eulachon should be fished if/when they returned in sufficient numbers. Despite political and social differences among groups, there was general agreement about future fishing and management priorities, which were largely based in Nuxalk knowledge and practices.

Focused on "getting it right," accurate interpretation, articulation, and representation of Nuxalk knowledge was a fundamental priority of the project. In keeping with Nuxalk protocol, this was addressed through an iterative process emphasizing adaptation, active listening, and attention to detail. Throughout the process of learning about sputc, the first author (project coordinator) took the lead in documenting knowledge shared by community members (including text, images, quotes, stories, and language), and facilitated its assessment and interpretation through the project team. Project leadership and the advisory committee decided on how to articulate and present emerging project material to the community and collaborators during project-related events. Soliciting further input and feedback in a cyclical process of knowledge gathering and sharing enabled reflexivity on the part of the research team, enabling the team to adapt the project as their knowledge, understanding, roles, and relationships evolved.

After months of knowledge documentation and sharing, the project team and knowledge holders were faced with the task of defining how Nuxalk eulachon knowledge be represented, and in what form. It proved challenging to envision the format of the final product, even after clearly defining goals and desired outcomes. Nuxalk knowledge is complex, oral, and family held, with important implications for its representation and authority for its use (McIlwraith 1992, Hanuse 2010, Kramer 2011, Beveridge 2019). Many Nuxalkmc questioned the appropriateness of documenting and representing Nuxalk knowledge in a stagnant or written form, and suggested the project employ practical (e.g., net making) or story-telling activities to share gathered knowledge. However, the urgency of preserving eulachon knowledge for future generations and the importance of obtaining community authority for future management planning were also well-recognized. The project team resolved to create a book that would serve as a foundation of Nuxalk eulachon knowledge and authority, supporting future knowledge transmission practices.

Over the next three years, the team produced 12 iterations of the book to solicit feedback on the selection, interpretation, structure, and representation of Nuxalk eulachon knowledge. The team had regular meetings and conversations with technical and cultural advisors to review and correct draft material, as well as with a broad range of Nuxalk members including elder fishers and grease-makers, teachers, community leaders, and language speakers. Feedback on book drafts was further solicited at Nuxalk meetings, luncheons, and cultural events, including the (now) annual sputc (eulachon) ceremony. As a support for future Nuxalk-driven projects and hands-on learning, the team aimed for the book to be accessible to a range of age groups and literacy levels. As it evolved, we imagined a grandmother reading the book with an 8-year old and asked ourselves if they would both be engaged and learning.

In the process of documenting and representing Nuxalk knowledge, the project team attended to its origins and context, accuracy and generalizability. For a specific element to be represented as common Nuxalk knowledge, we ensured that it was sourced from multiple people and multiple families of origin, and generally recognized by Nuxalkmc to be true. Meanwhile, individually held knowledge was attributed to its knowledge holder through the use of quotes. Attending to this level of detail required that we learn protocols of knowledge ownership to obtain permissions and give credit where appropriate. In recognition of Nuxalk knowledge systems, we used visual, narrative and practical sources, and materials to retain knowledge context, relationships, and origins, engaging Nuxalkmc through material like family photos and quotes recognized as authentic, useful, and personal. We also highlighted Nuxalk vocabulary, (personal) names, and place names, such that Nuxalkmc would see themselves reflected in the materials gathered, learning about their relationships to place. In appreciation of the strong Nuxalk visual traditions, a local Nuxalk artist (Wiiaqa7ay/Lyle Mack) illustrated the book's opening story and worked with a professional designer to ensure visual and design elements were appropriately mastered. 
Respecting place-based and relational knowledge in this way required a great deal of attention to the details of language and design, as well as care and perseverance with regard to credits, attributions, protocols, and permissions. Such learning required time, dedication, and capacity development of all team members. Although every attempt was made to employ a narrative mode of representation (e.g., using a story to structure the book), doing so proved difficult given the particular capacity of the core project team; although contracting a Nuxalk illustrator helped bring in a holistic element, we learned that it was difficult to fit or "flow" an Indigenous story into a western medium. In the end, some fragmentation and linearization of knowledge was necessarily imposed by the book format. Many Nuxalkmc recognize the limitations of this hybrid format, holding that local knowledge may only be fully understood in context, through application and practice by Nuxalkmc (Hanuse 2010, Beveridge 2019). However, this compromise was deemed necessary as a means to ensure that multi-media sputc knowledge was documented for future generations, and that this knowledge had great value in contemporary Nuxalk life.

\section{Community engagement and relationships}

Community engagement was one of the primary mandates of the Sputc Project, which prioritized relationship-building and trust as it engaged Nuxalk ways of knowing. The project team found that the idea of working "in a good way" (Ball and Janyst 2008, Kovach 2009) resonated with Nuxalkmc, so we used this language in the communication of our intents. From inception to completion, we kept Nuxalkmc abreast of our progress and invited them to contribute to the project through mail flyers and outreach at community events, including open houses, cultural events, and elders' luncheons. Because of our consistent presence in the community, the project became familiar to many, which led to greater level of awareness and investment on the part of the Nuxalk community. Prioritizing respectful relationships over anticipated timelines allowed for ebb and flow of individual availability and energy, and respect for conflicting community priorities (e.g., funeral protocols, fish harvesting). As a result, the project took place at a pace set by the community.

However, continuous engagement of Nuxalkmc beyond the project team and a core group of supporters remained a challenge throughout the project. Attendance at project events (open houses, workshops) was lower than related cultural events and activities (ceremony, grease-making), despite persistent efforts. Although financial incentives in the form of honoraria were provided to consistent and more knowledgeable advisors, incentivizing participation across family, social, and political obstacles was difficult for western-style meetings. Many Nuxalkmc were busy conducting day-to-day business, and pressing needs and established relationships took precedence over a long-term, seemingly abstract project with applications that may have been difficult to envision at the time. Indeed, capacity of all kinds is limited in small, isolated communities like Bella Coola; peoples' time and energy are spread thin, and there are many conflicting priorities. Further, a small number of Nuxalkmc are opposed to any project related to western eulachon science (which is perceived to be killing eulachon), whereas others do not support projects housed under the Nuxalk Administration Building, a site of perceived neocolonial influence because of its origins in the Indian Act (Joseph 2018), and ongoing role in administering related government funds. Although we attempted to engage the community as a whole, we also remained aware of situational factors, attentive to differences in participation and limitations to our reward structures. As such, it is certain that some Nuxalkmc had more involvement and influence in the project than others, depending on individual family relationships, community position, knowledge, and means.

Indeed, the project was necessarily situated in a network of relationships within the community. Nuxalkmc team members drew on established, long-standing connections with the Band administration, schools, cultural workers, and family units to which they were accountable. Attention to the full network of relationships to which we were accountable helped frame and motivate the project's process. The advisory committee played a key role in establishing project credibility in the eyes of the community. Meanwhile, the annual eulachon ceremony (2014present) demonstrated the Stewardship Office's continued commitment to and understanding of the importance of spiritual practice and community connection as it related to this work. Each of our relationships extended beyond those explicitly involved in the project, beyond family relationships, and into the spirit and animal worlds. As project team members, we listened to ancestors' voices, conducted ceremonies by the river, and sought to strengthen our relationships with the eulachon itself. We learned that reframing management as a cultural activity was key to community engagement. Ultimately, we understood that our purpose was to serve eulachon (and by extension, the community), a commitment that continues to this day.

\section{Knowledge sharing and outcomes}

The Sputc Project culminated in a 172-page, full-color book called Alhqulh ti Sputc (Sputc Project Team 2017, Beveridge 2019). Grounded in Nuxalk ways of knowing both ancestral and contemporary, the book was intended for use by Nuxalk leaders, educators, and community members, not for interpretation by non-Nuxalk. Before printing, 19 Stataltmc approved a final draft of the book, validating it as a foundation of Nuxalk knowledge about eulachon and advocating its application in future eulachon stewardship, thus demonstrating a remarkable level of support and cohesion. Those who did not sign approval did so for reasons unrelated to the form or content of the book.

Following Nuxalk protocol, a community feast was held to introduce and distribute the book, while affirming its validity (Thompson 2017). Despite summer vacations and widespread forest fires compromising peoples' presence and availability, over 300 people enjoyed a traditional meal of salmon, smoked eulachon, grease, and herring eggs. An illustrated story from the book was told aloud in both Nuxalk language and English, and instruction on how to do the sputc ceremonial dance was given. The project team received high praise from Nuxalk Stataltmc, who upheld the project as a model for future Nuxalk knowledge documentation and representation. Meanwhile, a standing ovation from the community at large suggested that the Sputc Project had succeeded in engaging a broad range of Nuxalkmc on the topics of eulachon values, stewardship, and governance, and in producing an outcome that was accessible, authentically Nuxalk, and valued by Nuxalkmc. A copy of the book was made accessible to all Nuxalkmc over the age of 12 , as well as to community organizations and schools. Since the ceremony, over 
580 copies of the book have been distributed, and it has begun to be used in school curriculum development and for Nuxalk Radio programming. Nuxalkmc report that the book authentically represents Nuxalk eulachon history and stewardship priorities, promoting pride and responsibility related to eulachon stewardship and ancestral governance (Beveridge 2019).

\section{DISCUSSION}

Although the Sputc Project process shared many commonalities with community-based methodologies, its distinctly Nuxalk approach was key to its success. The details of this case study may be specific to the Nuxalk context, sharing generalized insights about the key ingredients of Indigenous-driven research is possible without ascribing to a pan-Indigenous perspective. To this end, we provide: (1) a discussion of how the Sputc Project reflected and enacted key Indigenous research principles; and (2) consideration of the Sputc Project in relation to related academic work in terms of its relationship to Indigenous, decolonizing, and community-based research, including insights on choosing Indigenous and community-based methodologies in the context of environmental research and beyond.

\section{Engaging Indigenous knowledge}

In considering how Nuxalk people and knowledge systems directed and influenced the Sputc Project process, four interrelated principles emerged: (1) relational accountability; (2) responsible, contextualized methods; (3) respectful representation; and (4) reflexivity. These echo principles previously outlined decolonizing and Indigenous methodologists to guide respectful mixed-methodology research in Indigenous contexts (Louis 2007, Wilson 2008, Kovach 2009, 2017, Carlson 2016). We consider how community-engaged and Indigenous perspectives informed the project in the enactment of these principles.

\section{Relational accountability}

Drawing on Nuxalk epistemology, the expressed intention of the Sputc Project was to learn and share Nuxalk eulachon knowledge "in a good way" (Ball and Janyst 2008, Kovach 2009, Stiegman and Castleden 2015). This intention is reflected in the Indigenous methodology literature as the principle of relational accountability (Louis 2007, Wilson 2008, de Leeuw et al. 2012, Latulippe 2015a, Carlson 2016). The Sputc Project owes much of its success to it being a Nuxalk project and Nuxalkmc team members' pre-existing relationships and positions in the community (to which each was accountable and responsible) as well as that the project team was predominantly Nuxalk. Respectful relationships deepened the community's investment in the project, the breadth and quality of knowledge shared, the accuracy of knowledge representation, and the credibility of the project. Among others, relationships with key political knowledge holders (Caine et al. 2009, LaVeaux and Christopher 2009) were key to our early engagement of local governance processes and protocols. This highlights the importance of Indigenous leadership because such relationships would have been challenging for researchers less resourced or cognizant of the local political context. Navigating the complex social and political landscape of the community and building comfortable relationships that promoted trust and knowledge sharing required a great deal of time and attention. Indeed, differences in the reception of settler and Nuxalkmc team members indicates the importance of recognizing insider-outsider relationships and their impact on research methods (Louis 2007, de Leeuw et al. 2012).

Enacting relational accountability also meant acknowledging Nuxalk teachings and values, protocols, and practices with attention to our responsibility to a network of relations that included extended community, ancestors, future generations, land, and spirit (Louis 2007, Wilson 2008, Smith et al. 2016). Given that relational knowledge is "nested, created, and recreated within the context of relationships with other living beings" (Kovach 2009:47), our responsibilities extended beyond project participants and their relations to the river, and to eulachon itself. Like Coombes et al. (2014), we found that emphasizing relationship to this degree, "ethics become method, data become life, landscape becomes author" (Coombes et al. 2014:850), and team members become friends (de Leeuw et al. 2012). Although community-based researchers also emphasize co-learning and mutual or reciprocal exchange with research participants (Wallerstein and Duran 2006, Castleden et al. 2008, 2012, Wulfhorst et al. 2008, LaVeaux and Christopher 2009, Mulrennan et al. 2012, Adams et al. 2014), engagement with the land and non-human beings may be an additional requirement in the application of Indigenous methodologies or decolonizing research (Carlson 2016).

\section{Responsible, contextualized methods}

Indigenous methodology specialists underline that conducting respectful, meaningful research requires an in-depth engagement with community authority and protocol (Louis 2007, Kovach 2009, 2017, Lavallée 2009, Carlson 2016, Crook et al. 2016, Whyte et al. 2016). Indeed, Kovach (2017) underlines that "protocols are ethics" in Indigenous research design. Applying distinct Nuxalk cultural and political protocol meant involving ancestral leadership in decision-making and advisory processes, ensuring broad Nuxalk community engagement, and affirming shared knowledge through payment, feasting, gifting, and food at gatherings (Wilson and Restoule 2010, Kovach 2017). Informed by an ethic of relationality and interdependence, this resulted in a research process that may be characterized as iterative, emergent, or cyclical, like many community-based processes (Israel et al. 1998, LaVeaux and Christopher 2009). Although the Sputc Project initially employed methods of knowledge documentation and interpretation reminiscent of communitybased research (e.g., interviews and participatory workshops), these methods were adapted as Nuxalk knowledge was engaged. Our methods became increasingly open-ended and reciprocal: interviews transformed into conversations, and workshops and meetings took the form of open talking circles. Contextualized iteration of knowledge documentation and interpretation processes revealed underlying meanings, values, and teachings that enabled us to remain responsible and accountable to Nuxalkmc, including project collaborators, community, future generations, lands, and ancestors.

During the Sputc Project, we included a diversity of knowledge sources and sharing processes to encourage peoples' interaction and interpretation of project materials, and found that partnering with ceremonial functions and lands-based activities (e.g., greasemaking) was key to our learning and engagement. That sputc- 
related cultural events and activities (ceremony, grease-making) were better attended than project events indicates the importance of lands- and practice-based research methods (McGregor 2004, Legat and Barnaby 2012, Simpson 2014, Wildcat et al. 2014), thus the importance of reframing management as a cultural or even ceremonial activity.

Research employing Indigenous methodologies necessarily seeks knowledge from "multiple and multidimensional sources" (both internal and external, including dreams, journaling, and ceremony), and implicit, "holistic, non-fragmented processes" (Kovach 2017:227), including stories and oral histories, narratives, personal accounts, conversation, and talking circles (Louis 2007, Archibald 2008, Kovach 2009, Coombes et al. 2014, Smith et al. 2016). As community researchers, we found that it was essential to account for generational differences in experience when engaging with knowledge-holders. For those referred to by late Nuxalk leader Qwatsinas as the "lost" generation (Kirk 1986:247), practical learning during early adulthood had been undermined by residential school and cultural assimilation (Alfred 2009, Joseph 2018). Meanwhile, younger people lacked experience as a result of eulachon's disappearance. As a result, there was a tendency for many Nuxalkmc to minimize their own value and legitimacy as knowledge-holders. We learned to listen carefully for (and value) second-hand and implicit knowledge.

Many Indigenous researchers also emphasize the essential role of language in transmitting cultural knowledge (Simpson 2011, 2017, Brown et al. 2012). Kovach (2017) suggested that to the extent that Indigenous epistemologies are engaged, research "ought to have a strong narrative component as part of its method and presentation of findings" (Kovach 2009:35). Indeed, narrative, visual, story-based, and conversational methods similar to those used in the Sputc Project are often employed to bridge community-based and Indigenous methodologies (Thomas 2005, Castleden et al. 2008, Lavallée 2009, Kovach 2010). Key to both approaches is a shift in the balance of power from researcher to participant, such that participants or collaborators direct content and tell their story on their own terms (Brown and Strega 2005, Kovach 2009). In this spirit, the Sputc Project strived to be consistent with reciprocal, relational ways of knowing, employing story and other "emotive, affective, and narrative practices" (Coombes et al. 2014:851) to highlight local ways of knowing and being, providing space for the fluidity of metaphor and symbolism, witnessing, and interpretation (Thomas 2005, Louis 2007, Kovach 2017).

\section{Respectful representation}

The Sputc Project's iterative process and adaptive methods were essential to our goal of "getting it right," a practice that Indigenous methodology specialists refer to as "respectful representation" (Absolon and Willett 2004, Louis 2007, Coombes et al. 2014, Kovach 2017). It was our experience that respectful articulation and representation of Nuxalk knowledge required appropriate direction, participation, and interpretation by Nuxalkmc throughout the project process. Emphasizing Nuxalkmc as the exclusive, autonomous originators and audience of project materials (Schnarch 2004, First Nations Information Governance Centre 2014) affected every decision point of the Sputc Project process.
When communicating with Nuxalkmc about the Sputc Project, we used the language of "learning" and "sharing" to make the process accessible and relatable. However, the process between learning and sharing, which Kovach (2009) and Archibald (2008) called "meaning making" (Archibald 2008, Kovach 2009) and we refer to as interpretation, articulation, and representation, may have been the most difficult part of "getting it right." By many accounts, we are not alone in this experience (Kovach 2009, 2017, Castleden et al. 2012, Coombes et al. 2014). Although often most apparent during the stage of knowledge sharing or dissemination, respectful representation is contingent on mindful actions throughout the research process (Absolon and Willett 2004, Louis 2007, Coombes et al. 2014, Kovach 2017). Although communitybased research methodologies emphasize the importance of representation and voice (Wallerstein and Duran 2006, Minkler 2010, Tobias et al. 2013), this may be borne of interest in accountability and power dynamics (Darroch and Giles 2014, Muhammad et al. 2015) rather than in respect for Indigenous knowledge sources and authority, as in the case of Indigenous methodologies (McGregor 2004, Kovach 2009). Analytic methods that extract or decontextualize knowledge are inconsistent with Indigenous methodologies (Wilson 2008, Kovach 2009, 2017, Castleden et al. 2012, Coombes et al. 2014), particularly in the absence of a local partner entrenched in the relevant Indigenous worldview (Castleden et al. 2012, Kovach 2017). Although community-based researchers advocate privileging collaborative analysis, many western research conventions in the context of resource management still assume analytic authority is held by the researcher (Castleden et al. 2012, Coombes et al. 2014). Indeed, community-based researchers often successfully collaborate with Indigenous partners in research initiation, design, and data collection, but experience challenges when it comes to collaborative analysis and reporting (Castleden et al. 2012, Mulrennan et al. 2012). This may point to an underlying reluctance "to consider more fundamental and ontological objections to collaboration" and an "ongoing expectation of scholarly authority over research design and implementation" (Coombes et al. 2014:848).

According to Leanne Simpson, the alternative to extractivism is respect, responsibility, relationship, and deep reciprocity (Klein 2013). However, "(r)eciprocity requires time and resources" (Carlson 2016:14). Like other community-engaged Indigenous research (Castleden et al. 2008, 2012, de Leeuw et al. 2012, Mulrennan et al. 2012, Adams et al. 2014, Coombes et al. 2014), the Sputc Project required extensive capacity and resources, time and trust. Fortunately, financial resources and time were provided by Nuxalk, academic, and funding partners. Sidestepping academic and institutional pressures often experienced by community-engaged researchers (Castleden et al. 2012, de Leeuw et al. 2012, Coombes et al. 2014) involved substantial commitment of time and resources; perseverance and a continued, long-term presence in the community were essential elements of success. Given this experience, not unlike many community-based researchers (Israel et al. 1998, Wallerstein and Duran 2006, Wulfhorst et al. 2008, Tobias et al. 2013), we recommend that researchers consider that the local resources needed for Indigenous people to participate as equal research partners are often in limited supply, and related tasks often falls to a few 
already overextended individuals. Time and resource commitments need to be explicitly outlined at the beginning of the research process.

\section{Reflexivity}

In keeping with their emphasis on relationality, both communitybased and Indigenous methodologies underline that responsible research requires "reflexivity" (Absolon and Willett 2005, Kovach 2009, Nicholls 2009). For example, based in critical theory, CBPR is primarily concerned with reflexivity insofar as it exposes the power relations within which knowledge is embedded, privileged, and re-created (Wallerstein and Duran 2006, de Leeuw et al. 2012, Darroch and Giles 2014, Muhammad et al. 2015). Based on Indigenous epistemologies, Indigenous methodologies' focus on reflexivity is more personal, highlighting the researcher's place in (and responsibility to) a network of established relationships and knowledge (Absolon and Willett 2005, Wilson 2008, Kovach 2009, Nicholls 2009, Absolon 2011). During the Sputc Project, reflexive meetings and conversations on the part of the research team enabled us to adapt the project methods and methodologies based on circumstances and input as our understanding, roles, and relationships evolved. Within and beyond the project team, explicit inclusion of prayer at the beginning of meetings and regular retreats or lands-based activities would have further facilitated a systematic, collective reflexive process (Nicholls 2009) based in Nuxalk protocols and practices.

\section{Distinguishing between research methodologies in Indigenous contexts}

Addressing epistemological differences is a necessary challenge of doing Indigenous research, touching on the core tenets of knowledge production and purpose (Kovach 2009). We underline the importance of interrogating who produces knowledge, for/ with whom, how (using what theory), and for what purposes (Smith 1999, Brown and Strega 2005, Kovach 2009). We consider the Sputc Project process to illustrate the distinctions between Indigenous and community-based methodologies, both in terms of their epistemological foundations and their orientation to the goals of decolonization and resurgence. Was it based in Indigenous or community-based methodologies and to what extent was the project decolonizing?

From its conception, the Sputc Project was fundamentally concerned with cultural and political resurgence, focused on knowledge (re)generation for and by Nuxalkmc, based on Nuxalk ways of knowing. Initiated and led by Nuxalk people, priorities, and knowledge, the Sputc Project constituted a distinctly Nuxalk approach to knowledge documentation, interpretation, articulation, and representation. From inception to completion, the project drew on distinct knowledge systems held by Nuxalk people, including cultural teachings, values, ancestral governance protocols, and decision-making practices. It was important for the project and book to be recognized by Nuxalkmc as authentically Nuxalk, which is to say, as being a true representation of Nuxalk history and knowledge. As such, Nuxalk project leaders and collaborators consider the project to be a Nuxalk-specific methodology.

However, non-Nuxalk perspectives necessarily influenced project processes and priorities, both through the biases of a nonNuxalkmc project coordinator and through the unavoidable influence of Nuxalkmc with western educations and influences.
Further, although the project engaged Nuxalk epistemologies, it also employed many methods informed by non-Nuxalk research approaches. Although aspiring to an entirely Nuxalk project, Nuxalk leadership utilized external funding, resources, and capacity (including co-lead author RB) to advance the project, as needed. This resulted in a mutually beneficial, hybrid research process serving both Nuxalk and academic purposes. As such, we must ultimately consider the Sputc Project a mixed Indigenous and community-based methodology, informed by both Nuxalk and western knowledge systems, or as a co-created research project according to Shirk et al.'s (2012) classification.

To consider the epistemological and methodological orientation of the Sputc Project, we also found it helpful to consider how Indigenous and community-based methodologies relate to the processes of decolonization and resurgence. Although some scholars position decolonizing or anti-colonial approaches in their own methodological category (Chalmers 2017), we understand decolonization to be an over-arching practice and goal capable of informing any research methodology (Carlson 2016, Fortier 2017). In this sense, both community-based and Indigenous methodologies may or may not fall under the umbrella of “decolonizing” (Kovach 2009, Evans et al. 2014). For example, community-engaged research (including science) that pushes back on colonial forces that continue to separate Indigenous people from ancestral lands and resources may be decolonizing in intent and practice. However, applying a generalized antioppressive lens, or "increasing the self-determination and participation of research subjects and upholding values of reciprocity", as in community-engaged research, is not in itself decolonizing (Tuck and Yang 2012, Carlson 2016:6).

Meanwhile, Indigenous methodologies may be decolonizing in that they constitute an act of resistance to external systems of knowledge production, emphasizing Indigenous peoples' "right to tell their own histories, recover their own traditional knowledge and culturally grounded pedagogies, epistemologies and ontologies" (Stewart-Harawira 2013:41, Coombes et al. 2014). However, Indigenous methodologies are not necessarily decolonizing: they also necessarily engage internal knowledge systems and ancestral intellectual traditions, supporting cultural and political resurgence, sometimes without engaging settlercolonial elements. (Re)emerging resurgent research is not focused on a struggle against settler-colonialism, but on (re)producing knowledge for and by Indigenous people (Alfred 2005, Corntassel 2012, Coulthard 2014, Simpson 2017, Asch et al. 2018, Corntassel et al. 2018). Leanne Simpson (2008) articulates that
...one of our most critical and immediate tasks in building an Indigenous resurgence is ensuring that the knowledge of our ancestors is taught to the coming generations. But, according to our intellectual traditions, how we do this is as important or perhaps more important than the product of our efforts... So, the first thing we must recover is our own Indigenous ways of knowing, our own Indigenous ways of protecting, sharing, and transmitting knowledge, our own Indigenous intellectual traditions. And we must begin to practice and live those traditions on our own terms (Simpson 2008:74).

This assertion echoes Linda Tuhiwai Smith's (1999) description of decolonizing methodologies as "centering our concerns and 
worldviews, and coming to know... from our own perspectives and for our own purposes" (Smith 1999:39). So doing requires learning and applying Indigenous knowledge related to cultural protocol, decision making, and governance systems (Smith 1999, Alfred 2005, Simpson 2008, Evans et al. 2014, Chalmers 2017), as we attempted through the Sputc Project.

Although the Sputc Project certainly aimed to de-center settler knowledge systems, decolonization (resistance to dominant power structures) was secondary to the primary goal of resurgence (emphasizing Nuxalk strength and knowledge sources); it was a Nuxalk research project whose success was based on Nuxalk knowledges and methodology. Meanwhile, situated at the intersection of community and academic research, our work is intended to serve as a bridge between the practical work of Indigenous resurgence and nation-strengthening, and decolonizing academic work related to Indigenous knowledge documentation, interpretation, and representation. It is firmly decolonizing in its intent, aiming to uphold the resurgent work of the Sputc Project and inform others doing similar work.

\section{CONCLUSION}

As scholars in environmental management and beyond seek to strengthen and decolonize their research practices, they require methodologies capable of respectfully engaging Indigenous people, knowledge, values, and priorities. We drew on our experience of the Nuxalk Sputc Project as a successful example of applying an Indigenous research approach in the context of eulachon management. Founded and led by the Nuxalk Stewardship Office in Bella Coola, the Sputc Project engaged Nuxalkmc in learning and sharing knowledge about eulachon history, values, and stewardship to create a foundation for Nuxalk eulachon management authority (Sputc Project Team 2017).

Engaging both Indigenous and community-based research perspectives, we suggested that the Sputc Project's distinctly Nuxalk approach was key to its success. In particular, engaging Nuxalk knowledge required relational accountability, responsible, contextualised methods, respectful representation, and reflexivity. This supported a Nuxalk-driven research approach distinct from community-based methodologies, increasing Nuxalk research capacity and strengthening self-determined decision-making authority (Beveridge et al. 2020). Although some of the learning from the Sputc Project may be directly applied to other local projects (e.g., research protocols, decision-making processes), the scale and extent of this project should not be underappreciated. Indeed, the most valuable elements of the process (including broad Nuxalk engagement, iterative, cyclical process, and local leadership) could not have been achieved without significant resources (organization, time, space, funding), community connections, and a long-term presence in the community.

For those interested in applying Indigenous methodologies and/ or engaging Indigenous perspectives in environmental management, we described an example of mixed Indigenous and community-directed research. Our intent is that this work should support Indigenous leaders, researchers, and allies to consider engagement with decolonizing and Indigenous theories in their own manner and for their own purposes. It may also serve as an example for those supporting Indigenous resurgence and selfdetermination in other substantive areas, or with other species. If and when Alhqulh ti Sputc is shared beyond the community, our work can provide complementary insight into the process underlying the project. Among others, we detail how the project adhered to community protocols, used Indigenous methods of engaging Nuxalk knowledge, and aimed for respectful articulation of knowledge.

Through the example of the Sputc Project, we shared theoretical and practical insights about distinguishing between Indigenous and community-based research methodologies, and the relationship of each to decolonizing and resurgent research approaches. We suggested that appropriately applying Indigenous methodologies has the potential to move research toward authentically and respectfully supporting Indigenous resurgence and self-determination in the interpretation, production, and articulation of knowledge used in environmental management and beyond. Meanwhile, decolonizing approaches can adopt many of the same values and principles, including respectful collaboration, engaging Indigenous knowledge, priorities, perspectives, and people. An informed understanding by community leaders and researchers of these methodological options, and selection of methods based on the positions and preferences of each, is key to promoting a balanced power relationship between partners in the choice of research methods.

Responses to this article can be read online at: https://www.ecologyandsociety.org/issues/responses. php/12702

\section{Acknowledgments:}

Stutwiniitulhap (thank you) to the Nuxalk community, Stataltmc, and community leaders for allowing this research to take place, and to Nuxalk lands and ancestors for allowing us to be here. Core Sputc Project advisors and collaborators Snxakila (Clyde Tallio), Nunanta (Iris Siwallace), and Nuximlaycana (Fiona Edgar); Sputc Project technical advisory committee Q'isinay (Horace Walkus), Numutsta (Louise Hilland), Sinuxim (Russ Hilland), and Suulxikuuts (Joanne Schooner); Nuxalk stewardship office and project team Skw'asmana (Angel Mack), Rhonda DettlingMorton (Plcwlaqs), Evangeline Hanuse (Umq'umkila), and Nicole Kaechele; culture, language, and visual advisors Lori George (Aycts'mqa), Karen Anderson (Skw'yac), Dale McCreery, and Wiiaqa7ay (Lyle Mack); Alhqulh ti Sputc co-writers Qwaxw (Spencer Siwallace), Asits'aminak (Andrea Hilland), Slts'lani (Banchi Hanuse), Sputc Project interviewees, and collaborators; Ernie Tallio and the Nuxalk Guardian Watchmen, Sq'mlhh (Jason Moody) and Nuxalk bear study/fisheries crews; Nuxalk Stataltmc; Wally Webber (Snxaluulhla), and Nuxalk Chief and Council; all of the other Nuxalkmc who helped me learn what is written here, their relations, ancestors, and elders; and to sputc.

\section{Data Availability:}

Datalcode sharing is not applicable to this article as related qualitative data is confidential and cannot be shared. 


\section{LITERATURE CITED}

Absolon, K. E. 2011. Kaandossiwin: how we come to know. Fernwood Books, Halifax, Nova Scotia, Canada.

Absolon, K., and C. Willett. 2004. Aboriginal research: berry picking and hunting in the 21st century. First Peoples, Child and Family Review. 1(1):5-17. https://doi.org/10.7202/1069581ar

Absolon, K., and C. Willett. 2005. Putting ourselves forward: location in Aboriginal research. Pages 97-126 in L. Brown and S. Strega, editors. Research as resistance: critical, Indigenous, and anti-oppressive approaches. Canadian Scholars' Press, Toronto, Ontario, Canada.

Adams, M. S., J. Carpenter, J. A. Housty, D. Neasloss, P. C. Paquet, C. Service, J. Walkus, and C. T. Darimont. 2014. Toward increased engagement between academic and indigenous community partners in ecological research. Ecology and Society 19(3):5. https://doi.org/10.5751/es-06569-190305

Alfred, T. 2005. Wasáse: Indigenous pathways of action and freedom. University of Toronto Press, Toronto, Ontario, Canada.

Alfred, G. T. 2009. Colonialism and state dependency. Journal of Aboriginal Health (November):42-60. [online] URL: https://jps. library.utoronto.ca/index.php/ijih/article/view/28982/23931

Archibald, J.-A. 2008. Indigenous storywork: educating the heart, mind, body, and spirit. UBC Press, Vancouver, British Columbia, Canada.

Artelle, K., J. Stephenson, C. Bragg, J. Housty, W. Housty, M. Kawharu, and N. Turner. 2018. Values-led management: the guidance of place-based values in environmental relationships of the past, present, and future. Ecology and Society 23(3):35. https://doi.org/10.5751/es-10357-230335

Asch, M., J. Borrows, and J. Tully. 2019. Resurgence and reconciliation: Indigenous-settler relations and Earth teachings. University of Toronto Press, Toronto, Ontario, Canada. https:// doi.org/10.3138/9781487519926

Ball, J., and P. Janyst. 2008. Enacting research ethics in partnerships with Indigenous communities in Canada: "do it in a good way." Journal of Empirical Research on Human Research Ethics 3(2):33-51. https://doi.org/10.1525/jer.2008.3.2.33

Battiste, M. 2005. Indigenous knowledge: foundations for First Nations. WINHEC: International Journal of Indigenous Education Scholarship 1:1-17. [online] URL: https://journals. uvic.ca/index.php/winhec/article/view/19251

Battiste, M., and J. Y. Henderson. 2000. Protecting Indigenous knowledge and heritage: a global challenge. UBC Press, Vancouver, British Columbia, Canada.

Berkes, F. 2012. Sacred ecology. Third edition. Routledge, New York, New York, USA.

Beveridge, R. 2019. Standing up for sputc: the Nuxalk Sputc Project, eulachon management and well-being. Dissertation. Social Dimensions of Health, University of Victoria, Victoria, British Columbia, Canada. [online] URL: https://dspace.library. uvic.ca/handle/1828/10830
Beveridge, R., M. Moody, G. Murray, C. Darimont, and B. Pauly. 2020. The Nuxalk Sputc (Eulachon) Project: strengthening Indigenous authority through community-driven research. Marine Policy 119(September):103971. https://doi.org/10.1016/j. marpol.2020.103971

Bohensky, E. L., and Y. Maru. 2011. Indigenous knowledge, science, and resilience: what have we learned from a decade of international literature on "integration"? Ecology and Society 16 (4):6. https://doi.org/10.5751/ES-04342-160406

Borrows, J., and J. Tully. 2018. Introduction. Pages 3-25 in M. Asch, J. Borrows, and J. Tully, editors. Resurgence and reconciliation: Indigenous-settler relations and earth teachings. University of Toronto Press, Toronto, Ontario, Canada.

Brant Castellano, M. 2004. Ethics of Aboriginal research. Journal of Aboriginal Health January:98-114. [online] URL: https://jps. library.utoronto.ca/index.php/ijih/article/view/28935/24063

Brown, H. J., G. McPherson, R. Peterson, V. Newman, and B. Cranmer. 2012. Our land, our language: connecting dispossession and health equity in an Indigenous context. Canadian Journal of Nursing Research 44(2):21. [online] URL: https://cjnr.archive. mcgill.ca/article/view/2349

Brown, L., and S. Strega. 2005. Research as resistance: critical, Indigenous and anti-oppressive approaches. Canadian Scholars', Toronto, Ontario, Canada.

Brunger, F., and D. Wall. 2016. "What do they really mean by partnerships?" Questioning the unquestionable good in ethics guidelines promoting community engagement in Indigenous health research. Qualitative Health Research 26(13):1862-1877. https://doi.org/10.1177/1049732316649158

Caine, K. J., C. M. Davison, and E. J. Stewart. 2009. Preliminary field-work: methodological reflections from northern Canadian research. Qualitative Research 9(4):489-513. https://doi. org/10.1177/1468794109337880

Canadian Institutes of Health Research, Natural Sciences and Engineering Research Council of Canada, and Social Sciences and Humananities Research Council of Canada. 2014. Tricouncil policy statement: ethical conduct for research involving humans 2014. Government of Canada, Ottawa, Ontario, Canada. [online] URL: https://www.cmcc.ca/Tri-Council $\% 20$ Policy $\%$ 20Statement.pdf

Carlson, E. 2016. Anti-colonial methodologies and practices for settler colonial studies. Settler Colonial Studies 7(4):496-517. https://doi.org/10.1080/2201473x.2016.1241213

Castleden, H., T. Garvin, and Huu-ay-aht First Nation. 2008. Modifying Photovoice for community-based participatory Indigenous research. Social Science and Medicine 66 (6):1393-1405. https://doi.org/10.1016/j.socscimed.2007.11.030

Castleden, H. E., D. Martin, A. Cunsolo, S. Harper, C. Hart, P. Sylvestre, R. Stefanelli, L. Day, and K. Lauridsen. 2017. Implementing Indigenous and western knowledge systems (Part 2): "you have to take a backseat" and abandon the arrogance of expertise. International Indigenous Policy Journal 8(4).

Castleden, H., V. Sloan Morgan, and C. Lamb. 2012. "I spent the first year drinking tea": exploring Canadian university 
researchers' perspectives on community-based participatory research involving Indigenous peoples. Canadian Geographer/ Géographe canadien 56(2):160-179. https://doi.org/10.1111/ j.1541-0064.2012.00432.x

Chalmers, J. 2017. The transformation of academic knowledges: understanding the relationship between decolonising and Indigenous research methodologies. Socialist Studies/Études Socialistes 12(1):97. https://doi.org/10.18740/s4gh0c

Coombes, B., J. T. Johnson, and R. Howitt. 2014. Indigenous geographies III: methodological innovation and the unsettling of participatory research. Progress in Human Geography 38 (6):845-854. https://doi.org/10.1177/0309132513514723

Corntassel, J. 2012. Re-envisioning resurgence: Indigenous pathways to decolonization and sustainable self-determination. Decolonization: Indigeneity, Education and Society 1(1).

Corntassel, J., T. Alfred, N. Goodyear-Ka'opua, N. K. Silva, H. K. Aikau, and D. Mucina, editors. 2018. Everyday acts of resurgence: people, places, practices. Daykeeper, Gloucester, UK.

Coulthard, G. S. 2014. Red skin, white masks: rejecting the colonial politics of recognition. University of Minnesota Press, Minneapolis, Minnesota, USA. https://doi.org/10.5749/ minnesota/9780816679645.001.0001

Creswell, J. W. 2008. Research design: qualitative, quantitative, and mixed methods approaches. Sage, Thousand Oaks, California, USA.

Creswell, J. W. 2012. Qualitative inquiry and research design: choosing among five approaches. Sage, Thousand Oaks, California, USA.

Crook, D. A., M. M. Douglas, A. J. King, and S. Schnierer. 2016. Towards deeper collaboration: stories of Indigenous interests, aspirations, partnerships and leadership in aquatic research and management. Reviews in Fish Biology and Fisheries 26 (4):611-615. https://doi.org/10.1007/s11160-016-9449-7

Darroch, F., and A. Giles. 2014. Decolonizing health research: community-based participatory research and post-colonial feminist theory. Canadian Journal of Action Research 15 (3):22-36.

de Leeuw, S., E. S. Cameron, and M. Greenwood. 2012. Participatory and community-based research, Indigenous geographies, and the spaces of friendship: a critical engagement. Canadian Geographer/Géographe canadien 56(2):180-194. https://doi.org/10.1111/j.1541-0064.2012.00434.x

de Leeuw, S., and S. Hunt. 2018. Unsettling decolonizing geographies. Geography Compass 12(7):e12376. https://doi. org/10.1111/gec3.12376

Denzin, N. K., Y. S. Lincoln, and L. T. Smith. 2008. Handbook of critical and Indigenous methodologies. Sage, Thousand Oaks, California, USA. https://doi.org/10.4135/9781483385686

Easby, A. 2016. Indigenous research methodologies. University of Victoria, Victoria, British Columbia, Canada; Participatory Research in Asia, New Delhi, India. [online] URL: https:// unescochair-cbrsr.org/pdf/resource/kp/UVic IRM.pdf
Evans, M., A. Miller, P. J. Hutchinson, and C. Dingwall. 2014. Decolonizing research practice: Indigenous methodologies, Aboriginal methods, and knowledge/knowing in P. Leavy, editor. Oxford handbook of qualitative research. Oxford University Press, Oxford, UK. https://doi.org/10.1093/oxfordhb/9780199811755.013 .019

Evering, B. 2012. Relationships between knowledge(s): implications for 'knowledge integration.' Journal of Environmental Studies and Sciences 2(4):357-368. https://doi.org/10.1007/ $\underline{\text { s13412-012-0093-9 }}$

First Nations Information Governance Centre. 2014. Ownership, control, access and possession $\left(\mathrm{OCAP}^{\mathrm{TM}}\right)$ : the path to First Nations information governance. First Nations Information Governance Centre, Ottawa, Ontario, Canada. [online] URL: https://achh.ca/wp-content/uploads/2018/07/OCAP FNIGC.pdf

Fortier, C. 2017. Unsettling methodologies/decolonizing movements. Journal of Indigenous Social Development 6 (1):20-36. [online] URL: https://umanitoba.ca/faculties/social_work/ media/V6i1-02 fortier.pdf

Garibaldi, A., and N. Turner. 2004. Cultural keystone species: implications for ecological conservation and restoration. Ecology and Society 9(3):1. https://doi.org/10.5751/es-00669-090301

Gauvreau, A., D. Lepofsky, M. Rutherford, and M. Reid. 2017. "Everything revolves around the herring": the Heiltsuk-herring relationship through time. Ecology and Society 22(2):10. https:// doi.org/10.5751/es-09201-220210

Hanuse, S. B. 2010. Cry rock [Film]. Smayaykila Films/Moving Images Distribution, Vancouver, British Columbia, Canada.

Harris, D. C. 2001. Fish, law, and colonialism: the legal capture of salmon in British Columbia. University of Toronto Press, Toronto, Ontario, Canada. https://doi.org/10.3138/9781442674912

Harris, D. C., and P. Millerd. 2010. Food fish, commercial fish, and fish to support a moderate livelihood: characterizing Aboriginal and treaty rights to Canadian fisheries. Arctic Review on Law and Politics 1:82-107.

Hart, M. A. 2010. Indigenous worldviews, knowledge, and research: the development of an indigenous research paradigm. Journal of Indigenous Voices in Social Work 1(1). [online] URL: https://scholarspace.manoa.hawaii.edu/bitstream/10125/15117/ vlil 04hart.pdf

Hill, R., C. Grant, M. George, C. J. Robinson, S. Jackson, and N. Abel. 2012. A Typology of Indigenous engagement in Australian environmental management: implications for knowledge integration and social-ecological system sustainability. Ecology and Society 17(1). https://doi.org/10.5751/es-04587-170123

Hilland, A. 2013. Extinguishment by extirpation: the Nuxalk eulachon crisis. Thesis. University of British Columbia, Vancouver, British Columbia, Canada. https://dx.doi. org/10.14288/1.0074234

Housty, W. G., A. Noson, G. W. Scoville, J. Boulanger, R. M. Jeo, C. T. Darimont, and C. E. Filardi. 2014. Grizzly bear monitoring by the Heiltsuk people as a crucible for First Nation conservation 
practice. Ecology and Society 19(2):70. https://doi.org/10.5751/ ES-06668-190270

Irlbacher-Fox, S. 2014. Traditional knowledge, co-existence and co-resistance. Decolonization: Indigeneity, Education and Society 3(3):145-158. [online] URL: https://jps.library.utoronto. ca/index.php/des/article/download/22236/18046/

Israel, B. A., E. A. Parker, Z. Rowe, A. Salvatore, M. Minkler, J. López, A. Butz, A. Mosley, L. Coates, G. Lambert, P. A. Potito, B. Brenner, M. Rivera, H. Romero, B. Thompson, G. Coronado, and S. Halstead. 2005. Community-based participatory research: lessons learned from the Centers for Children's Environmental Health and Disease Prevention research. Environmental Health Perspectives 113(10):1463-1471. https://doi.org/10.1289/ehp.7675

Israel, B. A., A. J. Schulz, E. A. Parker, and A. B. Becker. 1998. Review of community-based research: assessing partnership approaches to improve public health. Annual Review of Public Health 19(1):173-202. https://doi.org/10.1146/annurev.publhealth.19.1.173

Jones, R., C. Rigg, and E. Pinkerton. 2017. Strategies for assertion of conservation and local management rights:a Haida Gwaii herring story. Marine Policy 80:154-167. https://doi.org/10.1016/ j.marpol.2016.09.031

Joseph, B. 2018. 21 things you may not know about The Indian Act: helping Canadians make reconciliation with Indigenous peoples a reality. Indigenous Relations, Port Coquitlam, British Columbia, Canada.

Kindon, S., R. Pain, and M. Kesby. 2007. Participatory action research approaches and methods: connecting people, participation and place. Routledge, London, UK. https://doi. org/10.4324/9780203933671

Kirk, R. 1986. Wisdom of the elders: native traditions on the northwest coast : the Nuu-chah-nulth, Southern Kwakiutl, and Nuxalk. Douglas and McIntyre, Madeira Park, British Columbia, Canada.

Kirkness, V. J., and R. Barnhardt. 1991. First Nations and higher education: the four R's - respect, relevance, reciprocity, responsibility. Journal of American Indian Education 30(3):1-15.

Klein, N. 2013. Dancing the world into being: a conversation with Idle No More's Leanne Simpson. YES! Magazine. [online] URL: https://www.yesmagazine.org/social-justice/2013/03/06/dancing-theworld-into-being-a-conversation-with-idle-no-more-leanne-simpson

Kotaska, J. G. 2013. Reconciliation 'at the end of the day': decolonizing territorial governance in British Columbia after Delgamuukw. Dissertation. Resource Management and Environmental Studies, University of British Columbia, Vancouver, British Columbia, Canada. [online] URL: https:// open.library.ubc.ca/soa/cIRcle/collections/ubctheses/24/items/1.0074235

Kovach, M. 2005. Emerging from the margins: Indigenous methodologies. Pages 19-36 in L. Brown and S. Strega, editors. Research as resistance: critical, Indigenous and anti-oppressive approaches. Canadian Scholars', Toronto, Ontario, Canada.
Kovach, M. 2009. Indigenous methodologies: characteristics, conversations, and contexts. University of Toronto Press, Toronto, Ontario, Canada.

Kovach, M. 2010. Conversational method in Indigenous research. First Peoples Child and Family Review 5(1):40-48. [online] URL: https://fncaringsociety.com/sites/default/files/online-journal/vol5num1/ Kovach pp40.pdf

Kovach, M. 2017. Doing Indigenous methodologies - a letter to a research class. Pages 214-234 in N. K. Denzin and Y. S. Lincoln, editors. The Sage handbook of qualitative research. 5th edition. Sage, Thousand Oaks, California, USA.

Kramer, J. 2011. Switchbacks: art, ownership, and Nuxalk national identity. UBC Press, Vancouver, British Columbia, USA

Kuhnlein, H. V., F. Yeboah, M. Sedgemore, S. Sedgemore, and H. M. Chan. 1996. Nutritional qualities of ooligan grease: a traditional food fat of British Columbia First Nations. Journal of Food Composition and Analysis 9(1):18-31. https://doi. org/10.1006/jfca.1996.0004

Latulippe, N. 2015a. Bridging parallel rows: epistemic difference and relational accountability in cross-cultural research. International Indigenous Policy Journal 6(2). https://doi. org/10.18584/iipj.2015.6.2.7

Latulippe, N. 2015b. Situating the work: a typology of traditional knowledge literature. AlterNative: An International Journal of Indigenous Peoples 11(2):118-131. https://doi.org/10.1177/117718011501100203

Lavallée, L. F. 2009. Practical application of an Indigenous research framework and two qualitative Indigenous research methods: sharing circles and Anishnaabe symbol-based reflection. International Journal of Qualitative Methods 8 (1):21-40. https://doi.org/10.32920/14668779.v1

LaVeaux, D., and S. Christopher. 2009. Contextualizing CBPR: key principles of CBPR meet the Indigenous research context. Pimatisiwin 7(1):1. [online] URL: https://www.ncbi.nlm.nih.gov/ pmc/articles/PMC2818123/

Legat, A., and J. Barnaby. 2012. Walking the land, feeding the fire: knowledge and stewardship among the Tlicho Dene. Second edition. University of Arizona Press, Tucson, Arizona, USA.

Lepofsky, D., and M. Caldwell. 2013. Indigenous marine resource management on the Northwest Coast of North America. Ecological Processes 2(1):12. https://doi.org/10.1186/2192-1709-2-12

Louis, R. P. 2007. Can you hear us now? Voices from the margin: using Indigenous methodologies in geographic research. Geographical Research 45(2):130-139. https://doi.org/10.1111/ j.1745-5871.2007.00443.X

Low, M. 2018. Practices of sovereignty: negotiated agreements, jurisdiction, and well-being for Heiltsuk Nation. Dissertation. Resource Management and Environmental Studies, University of British Columbia, Vancouver, British Columbia, Canada. [online] URL: https://open.library.ubc.ca/soa/cIRcle/collections/ubctheses/24/ items/1.0375642 
Mack, J. 2006. Remembering Ista. Women and Environments International Magazine; Toronto (72/73):16-18.

McGregor, D. 2004. Coming full circle: Indigenous knowledge, environment, and our future. American Indian Quarterly 28 (3):385-410. https://doi.org/10.1353/aiq.2004.0101

McGregor, D. 2009. Linking traditional knowledge and environmental practice in Ontario. Journal of Canadian Studies 43(3):69-100. https://doi.org/10.3138/jcs.43.3.69

McIlwraith, T. F. 1992. The Bella Coola Indians. University of Toronto Press, Toronto, Ontario, Canada. https://doi. org/10.3138/9781442680548

Menzies, C. R. 2006. Traditional ecological knowledge and natural resource management. University of Nebraska Press, Lincoln, Nebraska, USA.

Minkler, M. 2010. Linking science and policy through community-based participatory research to study and address health disparities. American Journal of Public Health 100(S1). https://doi.org/10.2105/AJPH.2009.165720

Moody, M. 2008. Eulachon past and present. Thesis. University of British Columbia, Vancouver, British Columbia, Canada. [online] URL: https://open.library.ubc.ca/soa/cIRcle/collections/ ubctheses/24/items/1.0070785

Moore, C., H. E. Castleden, S. Tirone, and D. Martin. 2017. Implementing the Tri-Council policy on ethical research involving Indigenous peoples in Canada: so, how's that going in Mi'kma'ki? International Indigenous Policy Journal 8(2). https://doi. org/10.18584/iipj.2017.8.2.4

Muhammad, M., N. Wallerstein, A. L. Sussman, M. Avila, L. Belone, and B. Duran. 2015. Reflections on researcher identity and power: the impact of positionality on community based participatory research (CBPR) processes and outcomes. Critical Sociology 41(7-8):1045-1063. https://doi.org/10.1177/0896920513516025

Mulrennan, M. E., R. Mark, and C. H. Scott. 2012. Revamping community-based conservation through participatory research. Canadian Geographer/Géographe canadien 56(2):243-259. https://doi.org/10.1111/j.1541-0064.2012.00415.x

Nadasdy, P. 1999. The politics of TEK: Power and the "integration" of knowledge. Arctic Anthropology 36:1-18.

Nadasdy, P. 2003. Reevaluating the co-management success story. Arctic 56:321-440. https://doi.org/10.14430/arctic634

Nadasdy, P. 2005. The anti-politics of TEK: the institutionalization of co-management discourse and practice. Anthropologica 47(2):215-232.

Newell, D. 1993. Tangled webs of history: Indians and the law in Canada's Pacific Coast fisheries. University of Toronto Press, Toronto, Ontario, Canada.

Nicholls, R. 2009. Research and Indigenous participation: critical reflexive methods. International Journal of Social Research Methodology 12(2):117-126. https://doi.org/10.1080/13645570902727698

Nigel Haggan and Associates. 2010. The case for including the cultural and spiritual values of eulachon in policy and decision- making. Report for Fisheries and Oceans Canada. Fisheries and Oceans Canada, Vancouver, British Columbia, Canada. [online] URL: https://seannachie.ca/Website/Website-docs/Eulachon Values. pdf

Schnarch, B. 2004. Ownership, control, access, and possession (OCAP) or self-determination applied to research: a critical analysis of contemporary First Nations research and some options for First Nations communities. International Journal of Indigenous Health 1(1):80.

Senkowsky, S. 2007. A feast to commemorate - and mourn - the eulachon. BioScience 57(8):720. https://doi.org/10.1641/b570815

Shaw, W. S., R. D. K. Herman, and G. R. Dobbs. 2006. Encountering indigeneity: Re-imagining and decolonizing geography. Geografiska Annaler: Series B, Human Geography 88 (3):267-276. https://doi.org/10.1111/j.1468-0459.2006.00220.x

Shirk, J., H. L. Ballard, C. C. Wilderman, T. Phillips, A. Wiggins, R. Jordan, E. McCallie, M. Minarchek, B. V. Lewenstein, M. Krasny, and R. Bonney. 2012. Public participation in scientific research: a framework for deliberate design. Ecology and Society 17(2):29. https://doi.org/10.5751/es-04705-170229

Simpson, L. 2001. Traditional ecological knowledge: marginalization, appropriation, and continued disillusion. Pages 132-139 in Indigenous knowledge conference. University of Saskatchewan, Saskatoon, Saskatchewan, Canada.

Simpson, L. B. 2008. Lighting the eighth fire: the liberation, resurgence, and protection of Indigenous nations. ARP, Winnipeg, Manitoba, Canada.

Simpson, L. B. 2014. Land as pedagogy: Nishnaabeg intelligence and rebellious transformation. Decolonization: Indigeneity, Education and Society 3(3):1-25. [online] URL: https://jps.library. utoronto.ca/index.php/des/article/view/22170/17985

Simpson, L. B. 2017. As we have always done: Indigenous freedom through radical resistance. Third edition. University Of Minnesota Press, Minneapolis, Minnesota, USA.

Smith, L. T. 1999. Decolonizing methodologies: research and Indigenous peoples. Zed Books, London, UK.

Smith, L. T., T. K. Maxwell, H. Puke, and P. Temara. 2016. Indigenous knowledge, methodology and mayhem: what is the role of methodology in producing Indigenous insights? A discussion from Mâtauranga Mâori. Knowledge Cultures 4 (3):131-156.

Sputc Project Team. 2017. Alhqulh ti Sputc (The Eulachon Book). Nuxalk Stewardship Office, Bella Coola, British Columbia, Canada.

Stewart-Harawira, M. 2013. Challenging knowledge capitalism: Indigenous research in the 21 st century. Socialist Studies/Études Socialistes 9(1). https://doi.org/10.18740/s43s3v

Stiegman, M. L., and H. Castleden. 2015. Leashes and lies: navigating the colonial tensions of institutional ethics of research involving Indigenous peoples in Canada. International Indigenous Policy Journal 6(3). https://doi.org/10.18584/ iipj.2015.6.3.2 
Supreme Court of Canada. 1997. Delgamuukw v. British Columbia. Canada Supreme Court ruling 3 S.C.R. 1010, Case 23799. Supreme Court of Canada, Ottawa, Ontario, Canada. [online] URL: https://scc-csc.lexum.com/scc-csc/scc-csc/en/item/1569/ index.do

Thomas, R. A. 2005. Honouring the oral traditions of my ancestors through storytelling. Pages 237-254 in L. Brown and S. Strega, editors. Research as resistance: critical, Indigenous, and anti-oppressive approaches. Canadian Scholars', Toronto, Ontario, Canada.

Thompson, C. 2014. Community celebrates eulachon with sputc ceremony. Coast Mountain News. 7 April.[online] URL: https:// www.coastmountainnews.com/news/community-celebrates-eulachonwith-sputc-ceremony/

Thompson, C. 2017. Book of Eulachon - Alhqulh Ti Sputc presented to Nuxalkmc at community feast. Coast Mountain News. 4 April. [online] URL: https://www.coastmountainnews. com/community/book-of-eulachon-alhqulh-ti-sputc-presented-tonuxalkmc-at-community-feast/

Tobias, J. K., C. A. M. Richmond, and I. Luginaah. 2013. Community-based participatory research (CBPR) with Indigenous communities: producing respectful and reciprocal research. Journal of Empirical Research on Human Research Ethics 8(2):129-140. https://doi.org/10.1525/jer.2013.8.2.129

Tuck, E., and K. W. Yang. 2012. Decolonization is not a metaphor. Decolonization: Indigeneity, Education and Society 1(1):1-40.

Turner, N. J. 2020. From "taking" to "tending": learning about Indigenous land and resource management on the Pacific Northwest Coast of North America. ICES Journal of Marine Science 77:2472-2482. https://doi.org/10.1093/icesjms/fsaa095

Turner, N. J., and F. Berkes. 2006. Coming to understanding: developing conservation through incremental learning in the Pacific Northwest. Human Ecology 34(4):495-513. https://doi. org/10.1007/s10745-006-9042-0

von der Porten, S., J. Corntassel, and D. Mucina. 2019. Indigenous nationhood and herring governance: strategies for the reassertion of Indigenous authority and inter-Indigenous solidarity regarding marine resources. AlterNative: An International Journal of Indigenous Peoples 15(1):62-74. https://doi. org/10.1177/1177180118823560

von der Porten, S., D. Lepofsky, D. McGregor, and J. Silver. 2016. Recommendations for marine herring policy change in Canada: aligning with Indigenous legal and inherent rights. Marine Policy 74:68-76. https://doi.org/10.1016/i.marpol.2016.09.007

von der Porten, S., R. de Loë, and R. Plummer. 2015. Collaborative environmental governance and Indigenous peoples: recommendations for practice. Environmental Practice 17(02):134-144. https://doi.org/10.1017/s146604661500006x

Wallerstein, N. B., and B. Duran. 2006. Using community-based participatory research to address health disparities. Health Promotion Practice 7(3):312-323. https://doi.org/10.1177/15248$\underline{39906289376}$

Wallerstein, N., and B. Duran. 2010. Community-based participatory research contributions to intervention research: the intersection of science and practice to improve health equity. American Journal Of Public Health 100S(1):S40-S46. https://doi. org/10.2105/ajph.2009.184036

Weber-Pillwax, C. 2001. What is indigenous research? Canadian Journal of Native Education 25(2):166-174.

Whyte, K. P., J. P. Brewer, and J. T. Johnson. 2016. Weaving Indigenous science, protocols and sustainability science. Sustainability Science 11(1):25-32. https://doi.org/10.1007/ $\underline{\text { s11625-015-0296-6 }}$

Wildcat, M., M. McDonald, S. Irlbacher-Fox, and G. Coulthard. 2014. Learning from the land: Indigenous land based pedagogy and decolonization. Decolonization: Indigeneity, Education and Society 3(3):15.

Wilmsen, C. 2008. Negotiating community, participation, knowledge, and power in participatory research. Pages 1-22 in C. Wilmsen, W. Elmendorf, L. Fisher, J. Ross, B. Sarathy, and G. Wells, editors. Partnerships for empowerment: participatory research for community-based natural resource management. Earthscan, London, UK.

Wilson, D. D., and J.-P. Restoule. 2010. Tobacco ties: the relationship of the sacred to research. Canadian Journal of Native Education 33(1):29-45.

Wilson, S. 2008. Research is ceremony: Indigenous research methods. Fernwood, Winnipeg, Manitoba, Canada.

Winbourne, J. 2002. 2002 Central Coast eulachon project: final report of traditional ecological knowledge survey. WuikinuxvKitasoo-Nuxalk Tribal Council, British Columbia, Canada.

Wulfhorst, J. D., B. W. Eisenhauer, S. L. Gripne, and J. M. Ward. 2008. Core criteria and assessment of participatory research. Pages 23-46 in C. Wilmsen, W. Elmendorf, L. Fisher, J. Ross, B. Sarathy, and G. Wells, editors. Partnerships for empowerment: participatory research for community-based natural resource management. Earthscan, London, UK. 